\title{
Deep Brain Stimulation for Movement Disorders of Basal Ganglia Origin: Restoring Function or Functionality?
}

\author{
Thomas Wichmann ${ }^{1,2}$ • Mahlon R. DeLong ${ }^{1}$
}

Published online: 8 March 2016

(C) The American Society for Experimental NeuroTherapeutics, Inc. 2016

\begin{abstract}
Deep brain stimulation (DBS) is highly effective for both hypo- and hyperkinetic movement disorders of basal ganglia origin. The clinical use of DBS is, in part, empiric, based on the experience with prior surgical ablative therapies for these disorders, and, in part, driven by scientific discoveries made decades ago. In this review, we consider anatomical and functional concepts of the basal ganglia relevant to our understanding of DBS mechanisms, as well as our current understanding of the pathophysiology of two of the most commonly DBS-treated conditions, Parkinson's disease and dystonia. Finally, we discuss the proposed mechanism(s) of action of DBS in restoring function in patients with movement disorders. The signs and symptoms of the various disorders appear to result from signature disordered activity in the basal ganglia output, which disrupts the activity in thalamocortical and brainstem networks. The available evidence suggests that the effects of DBS are strongly dependent on targeting sensorimotor portions of specific nodes of the basal gangliathalamocortical motor circuit, that is, the subthalamic nucleus and the internal segment of the globus pallidus. There is little evidence to suggest that DBS in patients with movement disorders restores normal basal ganglia functions (e.g., their role in movement or reinforcement learning). Instead, it appears that high-frequency DBS replaces the abnormal basal ganglia
\end{abstract}

Thomas Wichmann twichma@emory.edu

1 Department of Neurology, Emory University School of Medicine, Atlanta, GA, USA

2 Yerkes National Primate Research Center, Emory University, Atlanta, GA, USA output with a more tolerable pattern, which helps to restore the functionality of downstream networks.

Keywords Parkinson's disease · Dystonia · Deep brain stimulation · Oscillation · Synchrony $\cdot$ Pathophysiology Basal ganglia circuits

\section{Introduction}

Neurosurgeons first targeted the basal ganglia for movement disorders in the 1930s, using ablative procedures, with emerging evidence that pathology in the basal ganglia was associated with movement abnormalities and a growing understanding of the anatomy of the basal ganglia and subcortical structures [1]. By the 1950s and 1960s, lesioning of the globus pallidus (pallidotomy) and the thalamus (thalamotomy) were widely performed for treating Parkinson's disease (PD), dystonia, and various forms of tremor. The successful introduction of levodopa for PD in the mid-1960s, however, spelled the nearly complete demise of functional stereotaxic surgery, other than thalamotomy for medically intractable tremor.

The revival in the early 1990s of pallidotomy as a treatment for PD resulted, in part, from the need for a more effective treatment for the unforeseen, and often disabling, levodopainduced motor complications (severe motor fluctuations and dyskinesias). Other factors were the growing understanding of the pathophysiology of basal ganglia disorders, including the development of circuit models of basal ganglia function and circuit dysfunction in movement disorders and studies in the newly introduced 1-methyl-1,2,3,6-phenyl-tetrahydropyridine (MPTP) primate model of parkinsonism [2]. Collectively, these advances provided a clear rationale and impetus for the revival of ablative procedures. The report by Laitinen et al. [3] in the early 1990s, of significant benefits of pallidotomy for 
both parkinsonism and levodopa-induced side effects, contributed greatly to the renewed use of this approach.

The return to ablative procedures was short-lived, however. Beginning in the late 1990s, the lesioning strategies were increasingly replaced by high-frequency deep brain stimulation (DBS), a reversible and adjustable form of neuromodulation that was perceived to be less invasive yet equally effective [4]. The use of DBS stems from the seminal publication by Benabid et al. [5], reporting that DBS of the thalamus was an effective treatment for tremor, which led to a replacement of thalamotomy. The successful application of DBS to the subthalamic nucleus (STN), following the report of reversal of parkinsonism with STN ablation in the MPTP primate model of parkinsonism [6], led to its widespread use for the treatment of PD and, later, dystonia. DBS is currently approved by the US Food and Drug Administration for use in patients with tremor, PD, dystonia, and obsessive compulsive disorder. DBS has also been explored for many other neurologic and neuropsychiatric disorders, including epilepsy, Alzheimer's disease, Tourette syndrome, and treatment-resistant depression [7].

The introduction of DBS and the use of electrophysiologic techniques to guide the placement of DBS electrodes also provided a unique opportunity to learn more about the pathophysiology of the disorders, as well as the mechanism of action of DBS. In this review, we first consider relevant anatomical and functional concepts of basal ganglia circuits and circuit dysfunction, and then discuss the current understanding of the pathophysiology of the two basal ganglia movement disorders most frequently being treated with DBS, PD and dystonia, and the proposed mechanism of action of DBS in treating these and related disorders.

\section{Functional/Anatomic Considerations of the Basal Ganglia Circuits}

The basal ganglia are key components of a family of largely segregated parallel cortical-subcortical circuits, which involve the cerebral cortex, basal ganglia, and the ventral thalamus $[8$, 9]. The circuits have been grouped and designated broadly as "motor", "oculomotor", "prefrontal", and "limbic", reflecting the perceived functions of the frontal cortical areas from which they originate and to which they return. Dysfunction within these circuits is generally associated with signs and symptoms that broadly reflect the functions of the cortical areas they serve. We will limit ourselves here to a description of the connectivity of the nodes of the motor circuit (without discussion of interneuronal processing), since their dysfunction, when propagated to downstream targets in the brainstem and thalamus, leads to the signs and symptoms of movement disorders, both hypokinetic (e.g., PD) and hyperkinetic (e.g., dystonia, chorea, ballismus, or motor tics).
Throughout its subcortical course, the motor circuit (included in Fig. 1) maintains its somatotopic organization and neuronal specificity, reflecting highly topographic projections $[8,10]$. This circuit originates in multiple pre- and postcentral sensorimotor areas, including the motor cortex (MC), premotor cortex, cingulate motor area, and the supplementary motor area. These areas project primarily to the putamen, the sensorimotor portion of the striatum $[8,10]$, terminating on two distinct populations of striatal medium spiny projection neurons (MSNs), which, in turn, send projections either to the external segment of the globus pallidus (GPe), or to the internal segment of the globus pallidus (GPi) and the substantia nigra pars reticulata (SNr), the two output nuclei of the basal ganglia. The monosynaptic striatal projection to $\mathrm{GPi} / \mathrm{SNr}$ is called the direct pathway, while the projection linking the striatum to the GPi/SNr by way of GPe and the STN is called the indirect pathway (see Fig. 1). All connections of the basal ganglia are inhibitory except for those from the STN. Another cortical input to the basal ganglia, the "hyperdirect" pathway, links frontal cortical areas directly to the GPi/SNR via topographic projections to the corresponding functional domains of the STN (Fig. 1) [11, 12].

Projections from the output nuclei, GPi/SNr, are sent to portions of the thalamus, terminating in the anterior ventrolateral thalamic nucleus (VLa) and the magnocellular portion of the ventral anterior nucleus, as well as the caudal intralaminar nuclei, that is, the centromedian and parafascicular nuclei $(\mathrm{CM} /$ $\mathrm{Pf}$ ). While CM/Pf projections are mostly part of a pallido-CM/ Pf-striatal feedback system (see below), cortical projections from VLa close the motor loop, sending efferents to respective precentral motor fields, the MC, SMA, premotor cortex, and cingulate motor area. The same GPi and SNr neurons that send their axons to the thalamus also project to the brainstem, terminating predominately in the pedunculopontine nucleus and tectum.

A major feature of basal ganglia output is that the $\gamma$ aminobutyric acid (GABA)ergic neurons in GPi and $\mathrm{SNr}$ are tonically active and inhibitory upon their projection targets in thalamus and brainstem. The basal ganglia motor circuit is thus viewed as holding the thalamic and brainstem networks in check [13-16], and the level of tonic and phasic inhibition is determined by the interplay of direct, indirect, and hyperdirect pathways at the level of GPi/SNr.

The arrangement of the intrinsic basal ganglia pathways into direct/indirect and hyperdirect pathways is incorporated into several interpretations of basal ganglia function, including the hypothesis that these pathways may play a role in action selection [e.g., 15, 17-19], the scaling of movement parameters [20], and, in a more general sense, "motor motivation", or action "vigor" [21], and cost/benefit aspects of actions [21, 22].

The role of the basal ganglia in action selection has been long considered to be one of the fundamental roles of these 




Fig. 1 Corticosubcortical motor circuits. Black arrows indicate inhibitory connections; gray arrows indicate excitatory connections. Basal ganglia, thalamus, and cerebellum are marked. $\mathrm{CM} / \mathrm{Pf}=$ centromedian and parafascicular nuclei of the thalamus; Cereb. Cortex $=$ cerebellar cortex $; \mathrm{CMA}=$ cingulate motor area; $\mathrm{DCN}=$ deep cerebellar nuclei; $\mathrm{DP}=$ direct pathway; $\mathrm{D} 1=\mathrm{D} 1$-like dopamine receptor subtype; D2 = D2-like dopamine receptor subtype; $\mathrm{GPe}=$ external segment of the

nuclei [23]. It is most often used in the sense that the basal ganglia play a role in making the most appropriate action for a given situation by selecting the optimal response and blocking competing ones [24]. The general concept that activation of the direct pathway facilitates movement, while activation of the indirect pathway reduces movement, is supported by recent optogenetic studies [25-27]. This general framework may have pathophysiologic relevance (see below), in that hypokinetic diseases such as PD are associated with increased basal ganglia output, while hyperkinetic diseases (such as dystonia or chorea) are associated with abnormally low basal ganglia output $[15,16]$.

In addition to influencing the direct and indirect pathways, the cerebral cortex can also influence basal ganglia output via the hyperdirect corticosubthalamic pathway. While much sparser than the indirect pathway, the hyperdirect projection has received increasing attention. By circumventing the striatum, it may provide a mechanism for cortical inputs to influence GPi and $\mathrm{SNr}$ output with shorter latencies and thereby assist in situations that require rapid "stop" responses to external and internal triggers [17, 19, 28-41]. globus pallidus; $\mathrm{GPi}=$ internal segment of the globus pallidus; $\mathrm{HP}=$ hyperdirect pathway; $\mathrm{IP}=$ indirect pathway; $\mathrm{MC}=$ motor cortex; $\mathrm{PMC}$ $=$ premotor cortex; $\mathrm{PN}=$ pontine nuclei; $\mathrm{PPN}=$ pedunculopontine nucleus; $\mathrm{SMA}=$ supplementary motor area; $\mathrm{SNc}=$ substantia nigra pars compacta; $\mathrm{SNr}=$ substantia nigra pars reticulata; $\mathrm{STN}=$ subthalamic nucleus; $\mathrm{VA} / \mathrm{VL}=$ ventral anterior and ventral lateral nuclei of the thalamus. Figure from Wichmann 2015 [339]

It is important to point out that some of the aforementioned hypotheses for the motor functions of the basal ganglia, in particular, a role of the basal ganglia in the initiation of movement, are difficult to reconcile with much of the available data. Combined single-cell/behavioral studies in primates have found highly specific changes in neuronal activity in relation to (trained) limb movements throughout the nodes of the motor circuit, particularly in relation to movement amplitude/velocity, However, the observed changes in discharge lag behind activity changes in the MC [42-45], and the activation of (antidromically identified) corticoputaminal neurons lags that of nearby corticofugal projections to brainstem and spinal cord [46, 47]. Moreover, lesions interrupting the output of the motor circuit in the sensorimotor territory of GPi in normal primates and individuals with PD or dystonia [48], following pallidotomy, have little or no effect on reaction times, although a slowing of movement is a consistent finding [49-52]. Of course, it could be argued that the basal ganglia might play a more direct role in the initiation of internally generated movements. The lack of obvious deficits in humans undergoing pallidotomy or animals following large bilateral lesions of GPi, however, does not 
support this. Collectively, these findings argue against a role of the motor circuit in the initiation and selection of movement and support a more general effect on speed and amplitude of movement or motor vigor.

It is likely that the projections of the motor circuit portions of GPi to the pallidal receiving areas of the thalamus and to the brainstem serve different functions. Studies of lesioning in the primate have found that pharmacologic (transient) inactivation of the basal ganglia receiving territory of the ventral motor thalamus resulted in a reduced number of internally or externally triggered movements and an increased reaction time (depending on the injection site), with no obvious effect on spontaneous movements outside the task [53]. Large bilateral permanent lesions interrupting the basal ganglia receiving areas and sparing the cerebellar receiving areas resulted in impaired motor learning without a significant effect on spontaneous movements, providing evidence for a role of the basal ganglia-thalamocortical components of the motor circuit in motor learning [54]. In contrast, interventions at the PPN level in primates seem to have more overt effects on spontaneous behavior, resulting in akinesia/bradykinesia [55]. The effects of functional surgery targeting the VLa and PPN in patients are mentioned below.

As stated above, collaterals from the pallido- and nigrofugal projections are also directed in a topographically specific manner to the intralaminar nuclei of the thalamus, that is, the $\mathrm{CM} / \mathrm{Pf}$ (see Fig. 1). The CM/Pf-striatal system is seen as providing sensory and salience information to the basal ganglia, which may assist in procedural and reinforcement learning and action selection (see below) [56, 57]. Lesions of CM, the motor portions of $\mathrm{CM} / \mathrm{Pf}$, have little or no effect in relieving akinesia/ bradykinesia in the MPTP-treated primate [58], although DBS of CM in patients with PD has been reported to be beneficial for dyskinesias in limited studies [59].

Collaterals from the basal ganglia output projections to that thalamus also reach the PPN (Fig. 1) [60-73]. The STN sends a more modest glutamatergic projection to PPN [74-76]. The PPN is a very heterogeneous structure, consisting of a caudolateral pars compacta (PPNc) and an anteromedial pars dissipata. Cholinergic cells predominate in PPNc, but PPNc and anteromedial pars dissipata also contain large populations of GABAergic or glutamatergic neurons [77-79]. The input and output relationships of the various neuron groups in the PPN have not been precisely determined, but it is known that the nucleus gives rise to projections to the basal ganglia, thalamus, basal forebrain, reticular formation, and spinal cord [69, 74, 80-93], thus being, at the same time, part of the extended basal ganglia family of nuclei [74], and a conduit of descending basal ganglia outputs. The function(s) of this nucleus are poorly understood, although portions of the (primate) PPN are implicated in the control of gait and balance because of overlap with the physiologically identified mesencephalic locomotor region and possibly other motor functions (see below).
Although it has long been believed that basal ganglia and cerebellar subcortical networks are segregated, there is growing evidence for highly specific anatomical connections and physiologic interactions between the basal ganglia and the cerebellum ([94]; see Fig. 1). Thus, it appears that both the basal ganglia and cerebellum participate and interact under normal conductions in motor and nonmotor functions, and that they share pathologic activity in certain movement disorders, such as parkinsonian tremor and some types of dystonia [95-98].

Basal ganglia networks are influenced by several neuromodulators. Among these, the effects of dopamine on striatal transmission play a central role in all models of basal ganglia function and in the proposed pathophysiologic mechanisms in both PD and dystonia. Dopamine is released in the striatum and other nodes of the motor circuit from terminals of projections from the substantia nigra pars compacta, and regulates the activity of the basal ganglia output neurons by facilitating corticostriatal transmission upon MSNs of the direct pathway and inhibiting corticostriatal transmission upon MSNs of the indirect pathway ([99-102]; Fig. 1). The net effect of striatal dopamine release appears to be to reduce basal ganglia output to the thalamus and other targets. According to the classic circuit model, this will result in increased overall movement. By contrast, a decrease in striatal dopamine release, as is seen in PD, leads to a decrease in movement. Dopamine also has effects in all other nodes of the basal ganglia-thalamocortical network. The specific effects of dopamine at sites outside of the striatum are poorly understood [103].

Striatal dopamine release also plays a role in procedural and reinforcement learning [e.g., 104-108], owing to synaptic plasticity and remodeling. In terms of procedural learning, the "associative" portions of the caudate nucleus appear to be involved in early phases of learning, while the "motor" putamen is more prominently engaged when animals execute previously learned movement sequences [109-118]. Hypotheses about the role of dopamine in reinforcement learning are closely tied to the finding that dopamine neurons fire in relation to (positive) prediction errors in rewarded tasks [119-125]. Substantia nigra pars compacta neurons also receive information about negative prediction errors, through connections that originate in the lateral habenula [126-131].

\section{Pathophysiology of Parkinsonism and Dystonia}

\section{Parkinsonism}

$\mathrm{PD}$ is a progressive multisystem neurodegenerative disorder that affects many regions of the central and peripheral nervous systems [132], and leads to a plethora of motor and nonmotor signs and symptoms. However, the cardinal motor features of $\mathrm{PD}$, constituting what is termed parkinsonism (including akinesia/bradykinesia, tremor, and muscular rigidity), are the 
most prominent aspects of the disease during the initial phases. They arise from dopamine loss in the basal ganglia, in particular the sensorimotor portions of the putamen. During later phases of the disease, other signs and symptoms emerge, specifically gait and balance problems, and cognitive impairments. It is widely believed that balance problems are the result of degeneration in the portion of the PPN that belongs to the mesencephalic locomotor region and/or degeneration of cholinergic cell groups [e.g., 90, 133-139]. Cognitive impairments are likely caused by a combination of factors, including the extension of significant dopamine loss to nonmotor portions of the basal ganglia, and the spread of pathology to prefrontal cortical regions [132].

Parkinsonism (as defined above) is highly responsive to the administration of levodopa, the precursor of dopamine. As mentioned, the long-term use of dopaminergic replacement therapies can have substantial side effects, especially the emergence of highly disruptive dyskinesias and unpredictable "off times" and motor fluctuations. These problems, together with medication-refractory tremor, are the major factors for the use of DBS in PD.

Early studies of primates in (nondyskinetic) MPTP-treated monkeys emphasized the importance of changes in the overall activity of striatopallidal pathways. Metabolic studies suggested [140, 141], and microelectrode recording studies demonstrated, a reduction of neuronal discharge in GPe, and increased activity in the STN, leading to increased excitatory drive upon the basal ganglia output nuclei, GPi, and $\mathrm{SNr}$ [142-145], all strongly implicating increased activity over the indirect pathway in the pathophysiology of PD. Based on this evidence, models were developed positing that akinesia/bradykinesia results from excessive inhibitory output from GPi $[13,15,16]$, and emphasizing the role of increased GPi output in hypokinetic and decreased output in hyperkinetic disorders.

It was later recognized, however, that changes in the patterning of activity in the basal ganglia are likely to be at least as important as rate changes for the development of parkinsonian motor signs [146]. Among these, abnormal bursting and oscillatory fluctuations of neuronal discharge are particularly noticeable [147-152]. Oscillatory activity can be identified in electrophysiological recordings of the activity of single neurons in $\mathrm{GPi}, \mathrm{SNr}, \mathrm{STN}$, and $\mathrm{MC}$ in animals and patients with PD [153]. The proportion of cells in STN and GPi that discharge in bursts is also greatly increased in parkinsonism [143, 144, 152, 154, 155]. Finally, a highly important parkinsonismrelated change in spontaneous discharge is the abnormal level of synchrony between neighboring neurons [144, 152]. It is not specifically known how changes such as burst discharges, oscillatory discharge, or abnormal synchrony develop in parkinsonism, although altered striatal output to the extrastriatal basal ganglia, changes in collateral inhibition in the external pallidum [156], or changes in the strength and morphology of synapses within the subthalamopallidal network of connections (see below and $[157,158]$ ) may contribute to correlated oscillatory activity in the output nuclei of the basal ganglia $[152,159,160]$.

It is clear that the synchronous oscillatory activity in populations of neurons in the nodes of the corticobasal ganglia motor circuit contributes to the finding of power spectral changes in recordings of local field potentials (LFPs) in patients with PD, as well as in animal models of the disorder [161]. LFP signals reflect membrane potential fluctuations, both subthreshold (synaptic potentials) and suprathreshold (spiking-related). The realization that the amplitude of LFPs depends on the degree of temporal alignment of the electrical activities of the neural tissue from which they originate has rendered the recording and analysis of LFP signals an important tool for the exploration of circuit-level synchrony.

The fact that implanted DBS electrodes can also be used to record electrical signals in patients with these conditions has been one of the major scientific benefits of the introduction of DBS technology and had a major impact on our thinking about the pathophysiology of parkinsonism and other neuropsychiatric disorders. LFP recordings in patients with PD, particularly in the dorsolateral motor regions of the STN and $\mathrm{GPi}$, have demonstrated oscillations in the $10-25 \mathrm{~Hz}$ (beta) range in the unmedicated state, and in the $60-80 \mathrm{~Hz}$ (gamma) range in the levodopa-treated state [152, 162]. It is thought that the overly strong beta-band LFP oscillation indicates that desynchronization processes of neurons within the circuitry fail in PD, which may contribute to the hypokinetic features of the disease. This has led to the proposal that beta-band LFP oscillations are antikinetic and strongly correlated with rigidity and bradykinesia [163], while gamma-band oscillations (a sign of desynchronization) are thought to be prokinetic [162]. Beta oscillations are viewed as normal for the resting or "idling" state; their reduction with movement onset may play a role in allowing movement to take place. Conceivably increased or persistent beta-band oscillations could disrupt movement initiation and execution, or may reflect the underlying impairment of movement initiation or even be a compensatory mechanism [164].

There is no evidence that LFP oscillations per se influence motor performance. The finding of LFP signals with greater amplitude in patients with PD may simply reflect the fact that the system is in a state of increased synchrony [152]. A similar caveat applies to the recently described finding of increased coupling between the amplitude of gamma-band oscillations and the phase of beta-band activity at the same location [165]. This finding likely corresponds to synchronized bursts of single cell activity (accounting for the broadband gamma-band peak) whose timing reflects an underlying beta-rhythm (accounting for the apparent entrainment of activity in the beta-band range).

Although it is tempting to attribute signs and symptoms to specific abnormalities in neuronal activity or LFPs in PD, the 
(causal) importance of any of the multiple changes in basal ganglia activity for the development of parkinsonism remains uncertain because they are not always found in animal models of parkinsonism, or in humans with PD, and, if they occur, tend to occur late in the development of parkinsonian signs in animal models, well after their onset [158-161].

Changes in the basal ganglia other than dopamine loss (but likely related to it) may also contribute to activity changes in the basal ganglia. These include a growing list of chronic morphological changes in the basal ganglia, affecting glutamatergic and GABAergic transmission in these structures. For instance, plasticity at glutamatergic synapses has been demonstrated in animal models of parkinsonism and in patients with PD, affecting the corticostriatal, thalamostriatal, and corticosubthalamic pathways [166-173]. Recent studies have suggested additional plasticity of the GABAergic collaterals within the GPe, as well as the pallidosubthalamic projection, the latter perhaps related to heterosynaptic homeostatic modulations, driven by $N$-methyl-D-aspartate receptor activation at corticosubthalamic synapses $[157,158,174]$. The fact that many of these changes can be identified in dopamine depletion models strongly suggests that they are a late consequence of dopamine loss, affecting brain areas rich in dopamine (like the striatum), as well as those with little direct dopamine input (e.g., the STN or the thalamus). It is not known whether these late morphologic changes are reversible.

The role of brain structures outside of the basal ganglia in the motor manifestations of PD remains uncertain. Traditional explanations focus on the transmission of abnormal patterns of activity via the basal ganglia-thalamocortical projections. However, as mentioned above, the available evidence suggests a more important role of the projections of GPi to the thalamus in motor learning than in movement execution. In contrast, interventions directed at the PPN have revealed significant motoric effects in animal experiments [55]. Thus, PPN inactivation in normal primates reduces body movements of arms, trunk, and legs [142-146], and PPN injection of a GABA-A receptor antagonist, or low-frequency stimulation of PPN, alleviates experimental akinesia in monkeys, presumably by increasing PPN activity [146-156]. This constellation of findings suggests the possibility that the descending basal ganglia projections to the brainstem may play a greater role in the pathophysiology of akinesia/bradykinesia and movement than is commonly assumed. A particular role of the PPN in the axial control of gait and balance, and in abnormalities of these functions in patients with movement disorders, is suggested by the fact that portions of the PPN are part of the brainstem locomotor region [90, 137, $138]$, and the finding that PPN neurons in this region degenerate in PD [133-136].

Finally, the cerebellar outflow pathways also seem to be involved in aspects of the pathophysiology of PD, specifically tremor [95, 175, 176], as suggested by imaging studies [177], and by the finding that, unlike other signs of the disease, parkinsonian tremor is effectively treated with surgical interventions targeting the cerebellar-receiving portions of the thalamus [178, 179]. While dopamine loss is, in some way, related to the expression of tremor, this parkinsonian sign is often less sensitive to dopamine replacement therapy than the other parkinsonian signs, and not strongly related to beta-band power in LFP signals recorded in the basal ganglia [163].

\section{Dystonia}

Dystonia is a heterogeneous hyperkinetic movement disorder "characterized by sustained or intermittent muscle contractions causing abnormal, often repetitive movements, postures, or both. Dystonia is often initiated or worsened by voluntary action and associated with overflow muscle activation" [180]. Co-contraction of agonist and antagonist muscles is common. Dystonia can be classified by the presence or absence of associated clinical manifestations, differentiating "isolated dystonia" from "combined dystonia", where dystonia appears as a component of other disorders, such as PD. In adults, focal forms of dystonia are common, whereas in children and young adults, generalized inherited forms of dystonia are more common, such as idiopathic torsion dystonia [DYT1; 181].

Physiologic studies in isolated generalized and focal hand dystonia have demonstrated evidence of a widespread loss of GABAergic inhibition, involving cortex, brainstem and spinal cord, evidence of abnormal sensorimotor integration, and abnormalities of synaptic plasticity [182]. Some forms of dystonia are clearly associated with basal ganglia dysfunction. For instance, dystonia may result from disturbances in dopaminergic transmission assumed to affect strongly basal ganglia activity [183]. Thus, dystonia may develop either acutely or delayed (tardive dystonia), in normal individuals treated with dopamine-receptor blocking agents, or can be a sign of other diseases with disturbed dopamine metabolism, such as PD, levodopa-responsive dystonia, or DYT1 [184-189]. Transient dystonia has also been observed in monkeys treated with the dopaminergic neurotoxin MPTP [190-192].

Studies in primate models have shown that dystonia is associated with a reduction of activity along the putamen-GPe connection, and increased inhibition of STN and GPi by GPe efferents [193, 194]. Based on pharmacologic studies, there seems to be a relative increase in the activity of striatal neurons of the direct pathway over those that give rise to the indirect pathway in dystonia [195, 196], and single-cell recording studies in patients undergoing functional neurosurgical treatments have demonstrated low discharge rates in both GPe and GPi [197-202], in distinction to the aforementioned changes in PD where GPi discharge rates are generally increased. The presence of lowfrequency discharge in the GPi in patients with dystonia is similar to that in other hyperkinetic disorders, including chorea/ ballismus and motor tics [197, 203, 204]. Other studies have shown the emergence of low-frequency oscillations in single- 
cell and LFP activities in the basal ganglia or thalamus [200, 201, 205-207], comparable with those found in PD. Electrocorticographic recordings over the MC in patients with isolated dystonia showed less coupling between the phase of beta-band oscillations and the amplitude of gamma-band oscillations than found in patients with PD [208].

In some types of dystonia, the cerebellum may also be involved, either alone or in conjunction with basal ganglia abnormalities [96, 98, 209, 210]. For instance, gene carriers of the autosomal dominant DYT1 and DYT6 dystonias show functional disturbances of cerebellar connections. DYT1 has a relatively low penetrance (about $30 \%$ ) that may result from an additional abnormality in thalamocortical projections, which may be protective in these cases [97, 211-213]. Subtle structural cerebellar pathology is suspected to occur in some forms of dystonia [214]. Interplay between the cerebellar and basal ganglia circuits in the development of dystonias is suggested by experiments aimed at replicating the pathophysiology of the genetically inherited rapid-onset dystonia parkinsonism [RDP; 210].

\section{DBS}

\section{Implantation and Programming}

Candidates for DBS therapy with PD or dystonia undergo placement of stimulating leads into the STN or GPi, guided by neuroimaging followed by electrical macrostimulation to assess clinical responses and sensory and motor thresholds. Microelectrode recording and mapping of the targeted area is used by some groups, prior to placement and testing of the DBS lead, since correct placement is critical to the success of DBS. An internal pulse generator (IPG), which is similar to a cardiac pacemaker, is simultaneously or subsequently implanted, usually in the subclavicular region, and connected to the electrode [215]. The currently available electrodes contain 4 separate contacts, spaced either 0.5 or $1.5 \mathrm{~mm}$ apart. Programming of the IPG is typically carried out 2-4 weeks after implantation of the electrodes, using a telemetric system by which the clinician can remotely select specific electrode contacts used for stimulation, their configuration for mono- or bipolar stimulation, and parameters, including frequency, pulse width, and amplitude of the stimuli. Several groups are currently working on improvements to the design of electrodes and pulse generators. Some of these efforts are mentioned below.

\section{Use of DBS in PD}

DBS is currently used to treat patients with PD for whom the signs and symptoms cannot be satisfactorily controlled by medications due to the development of side effects. Stimulation of the sensorimotor STN or GPi between 30 and $100 \mathrm{~Hz}$ is relatively ineffective for parkinsonian features, while benefit is seen around $100 \mathrm{~Hz}$ and above, using stimulation amplitudes of 2-4 V and pulse widths of $60-90 \mu \mathrm{s}$. The available data indicate that both STN and GPi DBS in patients with PD relieve tremor, rigidity, and bradykinesia [216-221], and may improve gait and postural control in some patients [222].

Although the STN is most commonly targeted for PD, both GPi and STN DBS have comparable benefits for the cardinal features of PD. The pros and cons of STN versus GPi targeting are debated [223], and the relative incidence of side effects and complications of either of these procedures have been the focus of considerable discussion [215, 224]. Differences between these procedures are, in part, explainable by anatomical differences between the STN and GPi. As illustrated in Fig. 2, the STN is surrounded by major fiber systems and receives direct input from the cortex via the hyperdirect pathway. The STN is much smaller than the GPi, making inadvertent activation of nonmotor areas and extrinsic fiber systems and side effects more

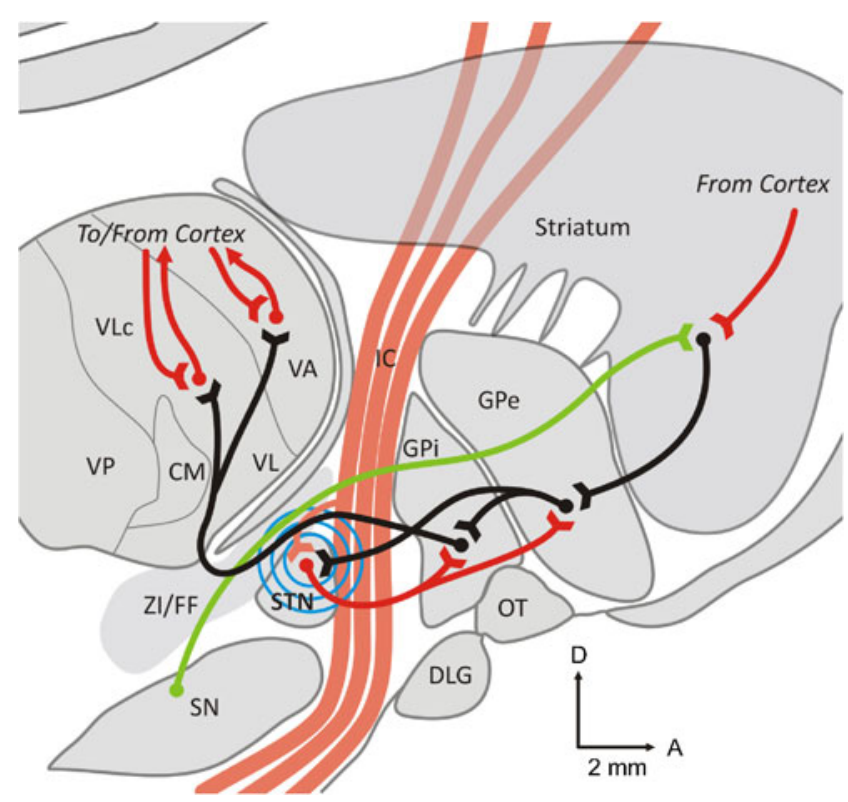

Fig. 2 Major anatomical pathways that are affected by subthalamic nucleus (STN) stimulation, and may contribute to the generation of cortical evoked potentials. Excitatory (glutamatergic) pathways are shown as red lines, inhibitory ( $\gamma$-aminobutyric acid-ergic) connections are shown as black lines, and modulatory dopaminergic fibers as green lines. The blue circles symbolize the spread of the electrical stimulation of the STN. CM= centromedian nucleus of the thalamus; $\mathrm{DLG}=$ lateral geniculate body; $\mathrm{FF}=$ Fields of Forel; IC = internal capsule; GPe = external pallidal segment; GPi = internal pallidal segment; OT = optic tract; Put = putamen; $\mathrm{SN}=$ substantia nigra; $\mathrm{VA}=$ ventral anterior nucleus of the thalamus; $\mathrm{VL}=$ ventrolateral nucleus of the thalamus; $\mathrm{ZI}=$ zona incerta. Figure from Devergnas and Wichmann 2011 [298], used with permission 
likely. The greater proximity and potential overlap of motor, associative, and limbic territories in this nucleus (compared with the larger GPi) contributes to the fact that DBS at this location is more likely to produce nonmotor effects than GPi DBS [225]. Another (unexplained) difference between these procedures is that the levodopa dose can usually be reduced in patients treated with STN DBS but not with GPi DBS.

Several other targets have been used to treat patients with PD. There is a general consensus among neurosurgeons that DBS of the ventral intermediate nucleus of the thalamus (Vim) is highly effective for tremor (but not other parkinsonian signs). Vim receives strong inputs from the cerebellum, and the effectiveness of tremor control with DBS at this location is a strong argument in favor of cerebellar involvement in the pathophysiology of tremor. PPN DBS [226-239], alone or in combination with STN or GPi DBS, is currently under study for patients with advanced PD who develop levodopaunresponsive freezing of gait, balance impairments, and falls. DBS of the PPN has been shown to be most effective at low stimulation frequencies [240]. However, the location of effective PPN stimulation sites remains debated [e.g., 231, 241]. Other groups have targeted the zona incerta and $\mathrm{CM}$ in patients with PD [7, 59], particularly for tremor or dyskinesias.

\section{Use of DBS for Dystonia}

There is strong evidence supporting the use of GPi DBS for the treatment of isolated generalized or segmental dystonia, as well as for patients with cervical dystonia [242, 243]. The stimulation parameters are typically the same as for PD, although some patients may also respond to lower frequencies. There is growing evidence supporting the use of GPi DBS for the treatment of tardive dystonia or myoclonus dystonia [244-254]. Lesser and inconsistent benefit is seen in dystonia secondary to structural brain damage [255]. DBS at other locations, particularly the STN, has also been found in pilot studies to be effective for isolated dystonia [256-262]. Compared with GPi DBS, STN DBS may offer the advantage of more rapid improvement for dystonia and reduced stimulation parameters [257]. While there is a prior history of thalamotomy for generalized dystonia, thalamic DBS has not been utilized for this indication, perhaps because of the success with GPi and STN DBS, although thalamic DBS (targeting Vim, or the thalamic ventralis oralis nucleus) is being explored for focal forms of dystonia, such as writer's cramp [263-265].

\section{Time Course of Responses}

The signs and symptoms of basal ganglia disorders respond to DBS with different time courses [266]. It seems intuitively clear that signs and symptoms that respond rapidly to DBS must be mediated by modulation of ongoing network activity, whereas signs and symptom that respond after longer delays may be the result of synaptic plasticity with gradual reshaping of synaptic activity or morphology. Most striking are the very short (seconds) latencies needed to treat essential tremor with thalamic DBS and rest tremor of PD with DBS in the STN. The response of appendicular rigidity and bradykinesia in $\mathrm{PD}$ with DBS delivered to the STN or GPi is likewise rapid.

At the other end of the time spectrum, the effects of GPi DBS for generalized dystonia may take days to begin and months to reach maximum effect, suggesting that short- and long-term plasticity may play a role [261]. Movementinduced limb dystonia responds more rapidly than fixed postural dystonia. It is also noteworthy that delayed temporal responses are the norm for both pallidotomy and DBS for dystonia, strongly suggesting that the mechanism of action may, in both cases, involves long-term plastic remodeling of cortical and brainstem mechanisms. The return of symptoms once DBS is turned off generally mirrors the time course of the onset times [267, 268].

\section{DBS Mechanism of Action}

Considering the complex anatomical connectivity and the relatively widespread effects of electrical stimulation with current DBS electrodes within the nodes of the basal ganglia motor circuit and beyond, it is no surprise that the mechanisms of action of DBS remain controversial. The early finding that DBS of the STN or GPi results in clinical benefits that are strikingly similar to those of lesioning at these sites for tremor and PD, respectively, suggested initially that DBS may act by inhibiting neurons in the area of stimulation [269-271]. This view was supported by the demonstration that some neurons in the vicinity of the stimulation site in STN and GPi in experimental animals and in patients with PD are, indeed, inhibited [272-275], perhaps by depolarization block or the release of GABA from terminals of afferents to the stimulated area [276-280].

Later electrophysiologic recording studies in primates and patients demonstrated that DBS has, in fact, multiple actions that may differ with the distance from the stimulation site and the spatial orientation of electrodes and neural elements studied [276, 277]. Axons are known to be more sensitive to stimulation than cell bodies [276, 277, 281-283], so that highfrequency DBS may alter the activity of axons emerging from a given area (this was specifically shown for STN and GPe DBS [283, 284]), thus leading to a functional blockade of transmission of information, whether pathological or normal, through the stimulated area, but without silencing of the tissue. This effect is summarized in the term "informational lesion" [285]. The concept that DBS produces an informational lesion provided an explanation for the fact that DBS is equally effective for a variety of hypo- and hyperkinetic disorders. 
Support for the idea that DBS produces an informational lesion comes from studies of evoked responses of GPi neurons to electrical stimulation of the MC [279]. In intact animals, such stimulation triggers triphasic response patterns in some GPi neurons, which are thought to be mediated via the sequential actions of the hyperdirect, direct, and indirect pathways [286]. GPi DBS was found to inhibit such stimulation-induced responses due to GABAergic inhibition of cell bodies [279].

Recent studies in awake behaving primates, however, have provided some evidence that physiologic sensorimotor-related discharge in the basal ganglia output nucleus (GPi) may be at least partially maintained during STN or pallidal DBS [266, 287]. These studies have suggested that DBS may act as a "selective filter" that permits some sensorimotor-related modulation of the activity of neurons in the stimulated area, while eliminating transmission of pathological low-frequency neuronal activity patterns.

The conclusion that DBS does not completely disrupt basal ganglia activities is also supported by the (limited) literature on the effects of DBS on motor learning. Contrary to the expectation that DBS of the STN or GPi would disrupt this important basal ganglia function, GPi DBS and STN DBS were, in fact, shown to improve performance in a motor sequence learning task or rewarded decision learning tasks [288-291]. Concomitant positron emission tomography studies suggested that the improvement after DBS was related to an enhancement of the activity of prefrontal or frontal corticobasal ganglia-thalamocortical loops [288, 291].

Yet another mechanism of action of DBS may be that it disrupts synchrony of neuronal discharge. This is suggested by studies in MPTP-treated monkeys [292]. Recent reports have provided additional evidence that pathological lowfrequency oscillations are reduced or decoupled between nodes of the basal ganglia thalamocortical circuits at clinically effective high-stimulation frequencies [293, 294]. Thus, it has been found in the MPTP-treated monkey that therapeutically effective STN DBS alters the pattern and power of oscillatory activity of neuronal activity in the motor thalamus, resulting in more regular firing patterns and significant changes in bursting activities [295]. Other recent studies in such animals have shown that clinically effective levels of GPi DBS also affected the firing rates and rhythmicity of cortical neurons [296, 297].

As is shown in Fig. 2, STN DBS, because of its location and proximity to nearby structures and fiber systems, could produce effects through a variety of mechanisms. Thus, STN DBS, with use of the contacts in the sensorimotor region of the nucleus, may stimulate nearby pallidal-thalamic fibers and cerebellar-thalamic fibers in the zona incerta, and may antidromically activate afferents from GPe, which send (inhibitory) collaterals to GPi. STN DBS may also directly activate the nigrostriatal tract [298], but this is unlikely to be relevant in the treatment of PD because of the degeneration of this pathway in PD.
Spread of stimulation from the STN stimulation site may also activate nearby corticospinal or corticobulbar fibers. STN stimulation has also been found to influence directly cortical neurons via antidromic activation of the corticosubthalamic pathway [298-301]. In fact, optogenetic studies in rodents have suggested that the antidromic activation of motor cortical input may be responsible for the clinical effects of STN DBS [299, 302]. While antidromic stimulation of cortex has also been shown in nonhuman primates and in patients, based on short-latency cortical-evoked potentials [298, 301, 303-305], it is not clear what role they play in the overall behavioral response to STN DBS in patients with movement disorders. Antidromic effects are not likely to play a prominent role in the case of GPi DBS [297, 298], which achieves the same motor result as STN DBS. Finally, a recent rodent study of STN DBS showed that STN DBS may also engage cerebellar activity to improve parkinsonian motor symptoms [306].

DBS has been shown to alter some of the electrophysiologic abnormalities observed in patients with movement disorders. For instance, STN DBS in patients with PD suppresses beta-band oscillations in the basal ganglia and reduces the aforementioned pathological coupling between beta-band phase and gamma-band amplitudes in MC [307-310]. GPi DBS also reduces beta-band oscillations in GPi and MC [297, 311]. These findings suggest that DBS may exert some of its effects by disrupting abnormal cortical synchronization. The fact that the clinical DBS effects are reflected in changes to electrophysiologic markers of disease severity may become practically relevant, as it may permit dynamic adjustment of DBS using closed-loop control designs (see below).

Based on animal studies, DBS may have effects on the release of growth factors (e.g., brain-derived neurotrophic factor), which may, in turn, promote neuroplasticity, neurogenesis, or neuroprotection [312-316]. At the present time there is no strong evidence from the human literature for a disease-modifying effect of DBS, although a recent study suggests that such effects may occur [317].

\section{Discussion}

The use of DBS has proven to be a major clinical advance for movement disorders and other neurologic conditions, and has already helped more than 150,000 patients to achieve better control of the signs and symptoms of their disease, and to improve their quality of life. However, despite intense research, the use of DBS remains largely empiric. Here, we make several general points about the lessons learned regarding the clinical effects and possible mechanisms of action of DBS. 


\section{The Removal of Abnormal Basal Ganglia Output is Sufficient to Treat Signs and Symptoms of Movement Disorders of Basal Ganglia Origin}

The experience with ablation and functional inactivation of the basal ganglia motor circuit in STN or GPi has shown that interruption of pathologic output can efficiently restore functionality for PD and dystonia and other hyperkinetic disorders. While DBS clearly has diverse effects on the stimulated brain areas, it is clear that the clinical benefits of DBS are not the result of a DBS-induced restoration of normal basal ganglia or brain function. Whether by inducing an "information lesion" or by acting as a "selective filter", DBS appears to override the impact of pathologic basal ganglia activity on downstream targets. The DBS-induced activities in the basal ganglia thalamocortical network are perhaps more stable, allowing normal short- and long-term plasticity to take place downstream from the site of DBS.

The fact that GPi or STN DBS is effective for both hypokinetic and hyperkinetic disorders is similar to the clinical experience with pallidotomy for these disorders. This reinforces the impression that the actual effects of the intervention (lesion or DBS) may not matter so much, as long as the activity of downstream areas of the brain are released from pathologic basal ganglia output, and are allowed to reach a new equilibrium that is conducive to an improved clinical state.

\section{The Basal Ganglia Assist (or Disturb) the Activities of Other Brain Regions}

A corollary of the preceding discussion is that the signs and symptoms of movement disorders do not necessarily represent or reflect the normal motor functions of the basal ganglia, but rather the dysfunction of the targeted thalamocortical and brainstem networks resulting from pathologic basal ganglia output in the motor circuit. In fact, the striking variety of clinical abnormalities of movement in clinical disorders of the basal ganglia seems to give a greatly exaggerated and distorted picture of the role and extent of basal ganglia participation in normal motor function as discussed earlier.

The finding that interruption of basal ganglia output by pallidotomy or thalamotomy (or DBS of basal ganglia or thalamus) relieves signs and symptoms of movement disorders, with modest effects on movement in patients and experimental animals, has been called the "paradox of stereotaxic surgery" [318]. The clinically identifiable impairments of pallidotomy appear to be only a small degree of bradykinesia and a minor disruption of reinforcement learning [51, 318-320]. As mentioned above, the available evidence suggests that GPi DBS or STN DBS does not disrupt procedural learning, and may even improve it
[288-291]. The absence of overt motor impairments with surgical disruption of basal ganglia output in patients with movement disorders does not negate a more significant function of the basal ganglia under normal conditions. The fact that the basal ganglia can be identified at the earliest stages in vertebrate evolution and that the evolutionary expansion of these structures mirrors that of the cerebral cortex is indirect evidence for their biological importance [23, 321]. However, the "paradox" suggests that the contribution of the basal ganglia to movement may be largely assistive rather than essential, and that its loss can be compensated for by the system as a whole with little deficit. The impression that it is "paradoxical" that the basal ganglia can be lesioned without major functional consequences may simply belie our failure to recognize that the clinical features of basal ganglia disorders do not represent or reflect the actual functions of the basal ganglia but dysfunction of the downstream networks resulting from propagated abnormal basal ganglia activity.

\section{Abnormal Levels of Synchrony may be a Fundamental Electrophysiologic Abnormality Resulting in Akinesia/Bradykinesia and Dystonia}

The use of DBS electrodes for recording purposes in humans, and in a large number of animal studies [44, $152,322-326]$, has emphasized that many of the identified electrical disease markers (e.g., oscillatory bursting or phase-amplitude coupling) can be explained by an abnormal level of synchronous neuronal discharge that may ultimately result in increased beta-band oscillations throughout the corticobasal ganglia circuits. Studies in the normal basal ganglia have shown that neighboring neurons tend to fire independently (e.g., [44, 45]), perhaps continuing at the cellular level what is readily apparent as circuit segregation at the macroanatomic level $[8,10]$. The finding of increased cross-correlation of single-cell discharge in many basal ganglia regions in animal models and patients with PD and increased LFP amplitudes in specific power spectral ranges indicates that the normal level of independence of discharge is substantially reduced in the parkinsonian state [44, 322, 323, 325, 326]. Effective antiparkinsonian therapies, including levodopa replacement and DBS reduce the LFP amplitudes to more normal levels, and reduce the abnormal synchrony of neurons in at least some brain regions [see, e.g., 152, 297, 327].

Studies in animal models of parkinsonism and in patients with PD have shown that parkinsonism is associated with peaks in power spectra of LFP signals. The location of these spectral peaks appears to differ between species, ranging from the theta-range of frequencies to the low gamma-range [328]. The exact spectral position of such 
peaks may be less important than the fact that there is a (low-frequency) peak at all, suggesting the presence of abnormally synchronized activity patterns that may interrupt cortical and brainstem operations. Synchrony of this kind is most easily studied with spectral methods, but it is not clear whether the disruptive synchrony has to be oscillatory in nature. For future research it may be fruitful to focus less on studies of spectral LFP peaks and more on the correlation of single-cell discharge. It is also worth emphasizing that, if synchrony between neurons is an important element of parkinsonism (and dystonia), these diseases may respond favorably to DBS regimes that specifically desynchronize circuit activities (see below).

\section{Technical Developments and Future of Neuromodulation}

Current DBS technology is essentially 25 years old. Engineers have already developed IPGs that deliver constant stimulation currents (rather than the conventional constant stimulation voltages) and are now developing pulse generators that will allow the use of more flexibly programmable stimulation regimes, allowing, for example, patterned stimulation instead of the currently available constant-frequency stimulation [329, 330]. Greater flexibility is desirable because it has been shown that intermittent or irregular stimulation may be as effective or even more effective than continuous stimulation [329, 331], and may help to preserve the battery life of the implanted devices. A related effort is that of developing stimulators that would allow the use of stimulation parameters that may desynchronize circuit activities [e.g., 332, 333] by stimulating with stimulation patterns that involve (in predetermined temporal sequences) multiple contacts in the stimulated area ("coordinated reset" stimulation). With regard to the disorders mentioned in this article, this approach has been used with some success in preliminary studies in MPTP-treated monkeys and in patients with PD $[333,334]$. In the patient study, coordinated reset stimulation was carried out for 2 short daily sessions over a period of 3 days. This resulted in antiparkinsonian effects that persisted for days. Over the 3-day trial periods, the patients showed a gradual decrease in beta-band power in their STN.

Device development also tries to address the fact that the signs of symptoms of basal ganglia diseases are not necessarily stable over time. While slow drifts in severity can be addressed by repeated (re-) programming of the existing devices, short-term fluctuations are not easily remedied with the current technology. The generation of closed-loop adaptive stimulation devices, a type of stimulation that dynamically adjusts the stimulation parameters according to the level of patient's disability is therefore a major development goal. The most pressing scientific and engineering issue in this effort is that reliable biomarkers for disease severity need to be found, and that the implanted device(s) must be able to detect them and adjust their output accordingly. In encouraging studies in parkinsonian primates it was shown that STN DBS triggered by the firing patterns of $\mathrm{MC}$ cortical neurons treated parkinsonism more effectively than conventional DBS [335], and subsequent studies in humans showed that STN DBS can be controlled by recorded LFP signals in the STN [336]. Major issues remain unsolved, including further optimization of the detection and extraction of the control signals, demonstration of the stability of the relationship between these signals and the disease signs and symptoms, and the obvious need to minimize battery consumption of the added sensing circuitry in the new devices.

The further development of new electrodes is also underway, with the goal of permitting more precise shaping and steering of the electrical field, through the use of multiple contacts along the electrode shaft [337, 338], in order to better control unintended spread and optimal shaping of current flow. Obviously, the freedom of being able to use additional electrode contacts must be balanced against the resulting more complex programming requirements.

\section{Conclusion}

The introduction of DBS had a strong impact on the treatment of movement disorders and other neuropsychiatric conditions, and has led to a better understanding of the pathophysiology of these disorders. The focus on neural networks and the mechanism of action of DBS have opened wide areas for further exploration in the form of novel targets and forms of stimulation for a variety of neuropsychiatric disorders.

DBS, although less invasive that ablation, is, nonetheless, an invasive procedure, requiring long-term care and maintenance. Moreover, although highly effective for nonprogressive disorders such as dystonia and the dopamine-responsive features of parkinsonism, it is a purely symptomatic treatment. While substantial refinements and progress is being made with current technology, other forms of neuromodulation may become important, in particular optogenetic and chemogenetic stimulation methods. Both techniques have the benefit of being cell-specific (through the use of cell-specific promoters) and less invasive, and may, therefore, produce benefits similar to those of DBS, but with fewer side effects. Major biological hurdles remain for both of these techniques, however. While it is hoped that less invasive and more effective forms of neuromodulation will be developed, it seems clear that DBS will undergo significant improvements and it is unlikely that it will be supplanted in the near future. 
Acknowledgments The writing of this article was supported by National Institute of Health grants P50-NS071669 (Udall Center grant), and P51-OD011132 (Yerkes Center base grant), and a grant by the American Parkinson's Disease Association to the Emory APDA Advanced Research Center.

Required Author Forms Disclosure forms provided by the authors are available with the online version of this article.

\section{References}

1. Guridi J, Lozano AM. A brief history of pallidotomy. Neurosurgery 1997;41:1169-80.

2. Wichmann T, DeLong MR, Guridi J, Obeso JA. Milestones in research on the pathophysiology of Parkinson's disease. Mov Disord 2011;26:1032-1041.

3. Laitinen LV, Bergenheim AT, Hariz MI. Leksell's posteroventral pallidotomy in the treatment of Parkinson's disease. J Neurosurg 1992; 76:53-61.

4. Hariz MI, Hariz GM. Therapeutic stimulation versus ablation. Handb Clin Neurol 2013;116:63-71.

5. Benabid AL, Pollak P, Gervason C, et al. Long-term suppression of tremor by chronic stimulation of the ventral intermediate thalamic nucleus. Lancet 1991;337:403-406.

6. Bergman H, Wichmann T, DeLong MR. Reversal of experimental parkinsonism by lesions of the subthalamic nucleus. Science 1990;249:1436-1438.

7. Hariz M, Blomstedt $\mathrm{P}$, Zrinzo L. Future of brain stimulation: new targets, new indications, new technology. Mov Disord 2013;28: 1784-1792.

8. Alexander GE, DeLong MR, Strick PL. Parallel organization of functionally segregated circuits linking basal ganglia and cortex. Annu Rev Neurosci 1986;9:357-381.

9. Middleton FA, Strick PL. Basal ganglia and cerebellar loops: motor and cognitive circuits. Brain Res Rev 2000;31:236-250.

10. Hoover JE, Strick PL. Multiple output channels in the basal ganglia. Science 1993;259:819-821.

11. Hartmann-von Monakow K, Akert K, Kunzle H. Projections of the precentral motor cortex and other cortical areas of the frontal lobe to the subthalamic nucleus in the monkey. Exp Brain Res 1978:33:395-403

12. Nambu A, Takada M, Inase M, Tokuno H. Dual somatotopical representations in the primate subthalamic nucleus: evidence for ordered but reversed body-map transformations from the primary motor cortex and the supplementary motor area. J Neurosci 1996; 16:2671-2683.

13. Deniau JM, Chevalier G. Disinhibition as a basic process in the expression of striatal functions. II. The striato-nigral influence on thalamocortical cells of the ventromedial thalamic nucleus. Brain Res 1985;334:227-233.

14. Chevalier G, Vacher S, Deniau JM, Desban M. Disinhibition as a basic process in the expression of striatal functions. I. The striatonigral influence on tecto-spinal/tecto-diencephalic neurons. Brain Res 1985;334:215-226.

15. Albin RL, Young AB, Penney JB. The functional anatomy of basal ganglia disorders. Trends Neurosci 1989;12:366-375.

16. DeLong MR. Primate models of movement disorders of basal ganglia origin. Trends Neurosci 1990;13:281-285.

17. Mink JW. The basal ganglia: focused selection and inhibition of competing motor programs. Progress in Neurobiology 1996;50: 381-425.

18. Nambu A. Seven problems on the basal ganglia. Curr Opin Neurobiol 2008;18:595-604
19. Nambu A, Tokuno H, Takada M. Functional significance of the cortico-subthalamo-pallidal 'hyperdirect' pathway. Neurosci Res 2002;43:111-117.

20. Georgopoulos AP, DeLong MR, Crutcher MD. Relations between parameters of step-tracking movements and single cell discharge in the globus pallidus and subthalamic nucleus of the behaving monkey. J Neurosci 1983;3:1586-1598.

21. Mazzoni P, Hristova A, Krakauer JW. Why don't we move faster? Parkinson's disease, movement vigor, and implicit motivation. J Neurosci 2007;27:7105-7116.

22. Hwang EJ. The basal ganglia, the ideal machinery for the costbenefit analysis of action plans. Front Neural Circuits 2013;7:121.

23. Grillner S, Robertson B, Stephenson-Jones M. The evolutionary origin of the vertebrate basal ganglia and its role in action selection. J Physiol 2013;591:5425-5431.

24. Mink JW, Thach WT. Basal ganglia intrinsic circuits and their role in behavior. Curr Opin Neurobiol 1993;3:950-957.

25. Bateup HS, Santini E, Shen W, et al. Distinct subclasses of medium spiny neurons differentially regulate striatal motor behaviors. Proc Natl Acad Sci U S A 2010;107:14845-14850.

26. Kravitz AV, Freeze BS, Parker PR, et al. (eds). Optogenetic dissection of basal ganglia circuit function in normal and parkinsonian mice. IBAGS X; 2010; Long Branch, NJ, USA.

27. Freeze BS, Kravitz AV, Hammack N, Berke JD, Kreitzer AC. Control of basal ganglia output by direct and indirect pathway projection neurons. J Neurosci 2013;33:18531-18539.

28. Verbruggen F, Logan GD. Models of response inhibition in the stop-signal and stop-change paradigms. Neurosci Biobehav Rev 2009;33:647-661.

29. Liddle EB, Scerif G, Hollis CP, et al. Looking before you leap: a theory of motivated control of action. Cognition 2009;112:141-158.

30. Band GP, van Boxtel GJ. Inhibitory motor control in stop paradigms: review and reinterpretation of neural mechanisms. Acta Psychol (Amst) 1999;101:179-211.

31. Aron AR, Poldrack RA. Cortical and subcortical contributions to Stop signal response inhibition: role of the subthalamic nucleus. J Neurosci 2006;26:2424-2433.

32. Chambers CD, Garavan H, Bellgrove MA. Insights into the neural basis of response inhibition from cognitive and clinical neuroscience. Neurosci Biobehav Rev 2009;33:631-646.

33. Kuhn AA, Williams D, Kupsch A, et al. Event-related beta desynchronization in human subthalamic nucleus correlates with motor performance. Brain 2004;127:735-746.

34. Aron AR, Durston S, Eagle DM, Logan GD, Stinear CM, Stuphorn V. Converging evidence for a fronto-basal-ganglia network for inhibitory control of action and cognition. J Neurosci 2007;27:11860-11864.

35. Eagle DM, Baunez C, Hutcheson DM, Lehmann O, Shah AP, Robbins TW. Stop-signal reaction-time task performance: role of prefrontal cortex and subthalamic nucleus. Cereb Cortex 2008;18: 178-188.

36. Isoda $\mathrm{M}$, Hikosaka $\mathrm{O}$. Role for subthalamic nucleus neurons in switching from automatic to controlled eye movement. J Neurosci 2008;28:7209-7218.

37. Eagle DM, Baunez C. Is there an inhibitory-response-control system in the rat? Evidence from anatomical and pharmacological studies of behavioral inhibition. Neurosci Biobehav Rev 2010;34:50-72.

38. Baunez C, Humby T, Eagle DM, Ryan LJ, Dunnett SB, Robbins TW. Effects of STN lesions on simple vs choice reaction time tasks in the rat: preserved motor readiness, but impaired response selection. Eur J Neurosci 2001;13:1609-1616.

39. Baunez C, Nieoullon A, Amalric M. In a rat model of parkinsonism, lesions of the subthalamic nucleus reverse increases of reaction time but induce a dramatic premature responding deficit. J Neurosci 1995;15:6531-6541. 
40. Baunez C, Robbins TW. Bilateral lesions of the subthalamic nucleus induce multiple deficits in an attentional task in rats. Eur J Neurosci 1997;9:2086-2099.

41. Hikosaka $\mathrm{O}$, Isoda $\mathrm{M}$. Brain mechanisms for switching from automatic to controlled eye movements. Prog Brain Res 2008;171:375-382.

42. Mitchell SJ, Richardson RT, Baker FH, DeLong MR. The primate globus pallidus: Neuronal activity related to direction of movement. Exp Brain Res 1987;68:491-505.

43. Turner RS, Anderson ME. Pallidal discharge related to the kinematics of reaching movements in two dimensions. J Neurophys 1997;77:1051-1074.

44. Wichmann T, Bergman H, DeLong MR. The primate subthalamic nucleus. I. Functional properties in intact animals. J Neurophys 1994;72:494-506.

45. Jaeger D, Gilman S, Aldridge JW. Neuronal activity in the striatum and pallidum of primates related to the execution of externally cued reaching movements. Brain Res 1995;694:111-127.

46. Turner RS, DeLong MR. Corticostriatal activity in primary motor cortex of the macaque. J Neurosci 2000;20:7096-7108.

47. Bauswein E, Fromm C, Preuss A. Corticostriatal cells in comparison with pyramidal tract neurons: contrasting properties in the behaving monkey. Brain Res 1989;493:198-203.

48. DeLong MR, Alexander GE, Mitchell SJ, Richardson RT. The contribution of basal ganglia to limb control. Prog Brain Res 1986;64:161-174.

49. Turner RS, Desmurget M. Basal ganglia contributions to motor control: a vigorous tutor. Curr Opin Neurobiol 2010;20:704-716.

50. Wichmann T, DeLong MR. Deep-brain stimulation for neurologic and psychiatric disorders. In: Steiner H, Tseng KY (eds). Handbook of basal ganglia structure and function. handbook of behavioral neuroscience. London: Academic Press (Elsevier); 2010. pp. 659-681.

51. Obeso JA, Jahanshahi M, Alvarez L, et al. What can man do without basal ganglia motor output? The effect of combined unilateral subthalamotomy and pallidotomy in a patient with Parkinson's disease. Exp Neurol 2009;220:283-292.

52. Mink JW, Thach WT. Basal ganglia motor control. III. Pallidal ablation: normal reaction time, muscle cocontraction, and slow movement. J Neurophys 1991;65:330-351.

53. van Donkelaar P, Stein JF, Passingham RE, Miall RC. Temporary inactivation in the primate motor thalamus during visually triggered and internally generated limb movements. J Neurophys 2000;83:2780-2790

54. Canavan AG, Nixon PD, Passingham RE. Motor learning in monkeys (Macaca fascicularis) with lesions in motor thalamus. Exp Brain Res 1989;77:113-126.

55. Nandi D, Jenkinson N, Stein J, Aziz T. The pedunculopontine nucleus in Parkinson's disease: primate studies. Br J Neurosurg 2008;22(Suppl. 1):S4-S8.

56. Galvan A, Smith Y. The primate thalamostriatal systems: Anatomical organization, functional roles and possible involvement in Parkinson's disease. Basal Ganglia 2011;1:179-189.

57. Fisher SD, Reynolds JN. The intralaminar thalamus-an expressway linking visual stimuli to circuits determining agency and action selection. Front Behav Neurosci 2014;8:115.

58. Lanciego JL, Rodriguez-Oroz MC, Blesa FJ, et al. Lesion of the centromedian thalamic nucleus in MPTP-treated monkeys. Mov Disord 2008;23:708-715.

59. Stefani A, Peppe A, Pierantozzi M, et al. Multi-target strategy for Parkinsonian patients: the role of deep brain stimulation in the centromedian-parafascicularis complex. Brain Res Bull 2009;78: 113-118.

60. Cebrian C, Parent A, Prensa L. Patterns of axonal branching of neurons of the substantia nigra pars reticulata and pars lateralis in the rat. J Comp Neurol 2005;492:349-369.

61. Beckstead RM. Long collateral branches of substantia nigra pars reticulata axons to thalamus, superior colliculus and reticular formation in monkey and cat. Multiple retrograde neuronal labeling with fluorescent dyes. Neurosci 1983;10:767-779.

62. Kha HT, Finkelstein DI, Pow DV, Lawrence AJ, Horne MK. Study of projections from the entopeduncular nucleus to the thalamus of the rat. J Comp Neurol 2000;426:366-377.

63. Spann BM, Grofova I. Nigropedunculopontine projection in the rat: an anterograde tracing study with phaseolus vulgarisleucoagglutinin (PHA-L). J Comp Neurol 1991;311:375-388.

64. Grofova I, Zhou M. Nigral innervation of cholinergic and glutamatergic cells in the rat mesopontine tegmentum: light and electron microscopic anterograde tracing and immunohistochemical studies. J Comp Neurol 1998;395:359-379.

65. Steininger TL, Rye DB, Wainer BH. Afferent projections to the cholinergic pedunculopontine tegmental nucleus and adjacent midbrain extrapyramidal area in the albino rat. I. Retrograde tracing studies. J Comp Neurol 1992;321:515-543.

66. Parent A, Mackey A, Smith Y, Boucher R. The output organization of the substantia nigra in primate as revealed by a retrograde double labeling method. Brain Res Bull 1983;10:529-537.

67. Harnois C, Filion M. Pallidofugal projections to thalamus and midbrain: a quantitative antidromic activation study in monkeys and cats. Exp Brain Res 1982;47:277-285.

68. Parent A, DeBellefeuille L. Organization of efferent projections from the internal segment of globus pallidus in primate as revealed by fluorescence retrograde labeling method. Brain Res 1982;245: 201-213.

69. Moon-Edley S, Graybiel AM. The afferent and efferent connections of the feline nucleus tegmenti pedunculopontinus, pars compacta. J Comp Neurol 1983;217:187-215.

70. DeVito JL, Anderson ME. An autoradiographic study of efferent connections of the globus pallidus in Macaca mulatta. Exp Brain Res 1982;46:107-117.

71. Shink E, Sidibe M, Smith Y. Efferent connections of the internal globus pallidus in the squirrel monkey: II. Topography and synaptic organization of pallidal efferents to the pedunculopontine nucleus. J Comp Neurol 1997;382:348-363.

72. Parent M, Levesque M, Parent A. The pallidofugal projection system in primates: evidence for neurons branching ipsilaterally and contralaterally to the thalamus and brainstem. J Chem Neuroanat 1999;16:153-165.

73. Parent M, Levesque M, Parent A. Two types of projection neurons in the internal pallidum of primates: single-axon tracing and threedimensional reconstruction. J Comp Neurol 2001;439:162-175.

74. Mena-Segovia J, Bolam JP, Magill PJ. Pedunculopontine nucleus and basal ganglia: distant relatives or part of the same family? Trends Neurosci 2004;27:585-588.

75. Smith Y, Hazrati LN, Parent A. Efferent projections of the subthalamic nucleus in the squirrel monkey as studied by the PHA-L anterograde tracing method. J Comp Neurol 1990;294:306-323.

76. Parent A, Smith Y. Organization of efferent projections of the subthalamic nucleus in the squirrel monkey as revealed by retrograde labeling methods. Brain Res 1987;436:296-310.

77. Jones BE, Beaudet A. Distribution of acetylcholine and catecholamine neurons in the cat brainstem: a choline acetyltransferase and tyrosine hydroxylase immunohistochemical study. J Comp Neurol 1987;261:15-32.

78. Lavoie B, Parent A. Pedunculopontine nucleus in the squirrel monkey: distribution of cholinergic and monoaminergic neurons in the mesopontine tegmentum with evidence for the presence of glutamate in cholinergic neurons. J Comp Neurol 1994;344:190209.

79. Rye DB, Saper CB, Lee HJ, Wainer BH. Pedunculopontine tegmental nucleus of the rat: cytoarchitecture, cytochemistry, and some extrapyramidal connections of the mesopontine tegmentum. J Comp Neurol 1987;259:483-528. 
80. Inglis WL, Winn P. The pedunculopontine tegmental nucleus: where the striatum meets the reticular formation. Prog Neurobiol 1995;47:1-29.

81. Garcia-Rill E. The pedunculopontine nucleus. Prog Neurobiol 1991;36:363-389.

82. Pahapill PA, Lozano AM. The pedunculopontine nucleus and Parkinson's disease. Brain 2000;123:1767-1783.

83. Jackson A, Crossman AR. Nucleus tegmenti pedunculopontinus: Efferent connections with special reference to the basal ganglia, studied in the rat by anterograde and retrograde transport of horseradish peroxidase. Neurosci 1983;10:725-765.

84. Sherman D, Fuller PM, Marcus J, et al. Anatomical location of the mesencephalic locomotor region and its possible role in locomotion, posture, cataplexy, and parkinsonism. Front Neurol 2015;6:140.

85. Lavoie B, Parent A. Pedunculopontine nucleus in the squirrel monkey: projections to the basal ganglia as revealed by anterograde tract-tracing methods. J Comp Neurol 1994;344:210-231.

86. Mena-Segovia J, Winn P, Bolam JP. Cholinergic modulation of midbrain dopaminergic systems. Brain Res Rev 2008;58:265-271.

87. Rye DB, Lee HJ, Saper CB, Wainer BH. Medullary and spinal efferents of the pedunculopontine tegmental nucleus and adjacent mesopontine tegmentum in the rat. J Comp Neurol 1988;269:315-341.

88. Vincent SR. The ascending reticular activating system-from aminergic neurons to nitric oxide. J Chem Neuroanat 2000;18:23-30.

89. Grofova I, Keane S. Descending brainstem projections of the pedunculopontine tegmental nucleus in the rat. Anat Embryol (Berl) 1991;184:275-290.

90. Garcia-Rill E, Simon C, Smith K, Kezunovic N, Hyde J. The pedunculopontine tegmental nucleus: from basic neuroscience to neurosurgical applications: arousal from slices to humans: implications for DBS. J Neural Transm 2011;118:1397-1407.

91. Muthusamy KA, Aravamuthan BR, Kringelbach ML, et al. Connectivity of the human pedunculopontine nucleus region and diffusion tensor imaging in surgical targeting. J Neurosurg 2007; 107:814-820

92. Aravamuthan BR, Muthusamy KA, Stein JF, Aziz TZ, JohansenBerg H. Topography of cortical and subcortical connections of the human pedunculopontine and subthalamic nuclei. Neuroimage 2007;37:694-705.

93. Benarroch EE. Pedunculopontine nucleus: functional organization and clinical implications. Neurology 2013;80:1148-1155.

94. Bostan AC, Dum RP, Strick PL. The basal ganglia communicate with the cerebellum. Proc Natl Acad Sci U S A 2010;107:8452-8456.

95. Hallett M. Tremor: pathophysiology. Parkinsonism Relat Disord 2014;20(Suppl. 1):S118-S122.

96. Prudente CN, Hess EJ, Jinnah HA. Dystonia as a network disorder: what is the role of the cerebellum? Neurosci 2014;260:23-35.

97. Niethammer M, Carbon M, Argyelan M, Eidelberg D. Hereditary dystonia as a neurodevelopmental circuit disorder: Evidence from neuroimaging. Neurobiol Dis 2011;42:202-209.

98. Neychev VK, Fan X, Mitev VI, Hess EJ, Jinnah HA. The basal ganglia and cerebellum interact in the expression of dystonic movement. Brain 2008;131:2499-2509.

99. Gerfen CR. Dopamine receptor function in the basal ganglia. Clin Neuropharmacol 1995;18:S162-S177.

100. Murer MG, Tseng KY, Kasanetz F, Belluscio M, Riquelme LA. Brain oscillations, medium spiny neurons, and dopamine. Cell Mol Neurobiol 2002;22:611-632.

101. Tseng KY, Kasanetz F, Kargieman L, Riquelme LA, Murer MG. Cortical slow oscillatory activity is reflected in the membrane potential and spike trains of striatal neurons in rats with chronic nigrostriatal lesions. J Neurosci 2001;21:6430-6439.

102. Wilson CJ, Kawaguchi Y. The origins of two-state spontaneous membrane potential fluctuations of neostriatal spiny neurons. J Neurosci 1996;16:2397-2410.
103. Rommelfanger KS, Wichmann T. Extrastriatal dopaminergic circuits of the basal ganglia. Front Neuroanat 2010;4:139.

104. Yin HH, Mulcare SP, Hilario MR, et al. Dynamic reorganization of striatal circuits during the acquisition and consolidation of a skill. Nat Neurosci 2009; 12:333-341.

105. Graybiel AM. Habits, rituals, and the evaluative brain. Annu Rev Neurosci 2008;31:359-387.

106. Graybiel AM. The basal ganglia: learning new tricks and loving it. Curr Opin Neurobiol 2005;15:638-644.

107. Pennartz CM, Berke JD, Graybiel AM, et al. Corticostriatal interactions during learning, memory processing, and decision making. J Neurosci 2009;29:12831-12838.

108. Kubota Y, Liu J, Hu D, et al. Stable encoding of task structure coexists with flexible coding of task events in sensorimotor striatum. J Neurophysiol 2009;102:2142-2160.

109. Miyachi S, Hikosaka O, Lu X. Differential activation of monkey striatal neurons in the early and late stages of procedural learning. Exp Brain Res 2002;146:122-126.

110. Nakahara H, Doya K, Hikosaka O. Parallel cortico-basal ganglia mechanisms for acquisition and execution of visuomotor sequences - a computational approach. J Cogn Neurosci 2001;13: 626-647.

111. Rand MK, Hikosaka O, Miyachi S, et al. Characteristics of sequential movements during early learning period in monkeys. Exp Brain Res 2000;131:293-304.

112. Hikosaka O, Nakahara H, Rand MK, et al. Parallel neural networks for learning sequential procedures. Trends Neurosci 1999;22:464-471.

113. Hikosaka O, Miyashita K, Miyachi S, Sakai K, Lu X. Differential roles of the frontal cortex, basal ganglia, and cerebellum in visuomotor sequence learning. Neurobiol Learn Mem 1998;70: 137-149.

114. Miyachi S, Hikosaka O, Miyashita K, Karadi Z, Rand MK. Differential roles of monkey striatum in learning of sequential hand movement. Exp Brain Res 1997;115:1-5.

115. Restivo L, Frankland PW. Shifting to automatic. Front Integr Neurosci 2010;4:1.

116. Ashby FG, Turner BO, Horvitz JC. Cortical and basal ganglia contributions to habit learning and automaticity. Trends Cogn Sci 2010;14:208-215.

117. Steele CJ, Penhune VB. Specific increases within global decreases: a functional magnetic resonance imaging investigation of five days of motor sequence learning. J Neurosci 2010;30: 8332-8341.

118. Swett BA, Contreras-Vidal JL, Birn R, Braun A. Neural substrates of graphomotor sequence learning: a combined FMRI and kinematic study. J Neurophysiol 2010;103:3366-3377.

119. Fiorillo CD, Tobler PN, Schultz W. Discrete coding of reward probability and uncertainty by dopamine neurons. Science 2003;299:1898-1902.

120. Waelti P, Dickinson A, Schultz W. Dopamine responses comply with basic assumptions of formal learning theory. Nature 2001;412:43-48.

121. Schultz W, Tremblay L, Hollerman JR. Reward processing in primate orbitofrontal cortex and basal ganglia. Cerebr Cortex 2000;10:272-284.

122. Schultz W, Dickinson A. Neuronal coding of prediction errors. Annu Rev Neurosci 2000;23:473-500.

123. Hollerman JR, Schultz W. Dopamine neurons report an error in the temporal prediction of reward during learning. Nat Neurosci 1998;1:304-309.

124. Schultz W, Dayan P, Montague PR. A neural substrate of prediction and reward. Science 1997;275:1593-1599.

125. Mirenowicz J, Schultz W. Preferential activation of midbrain dopamine neurons by appetitive rather than aversive stimuli. Nature 1996;379:449-451. 
126. Matsumoto M, Hikosaka O. Representation of negative motivational value in the primate lateral habenula. Nat Neurosci 2009;12: 77-84.

127. Wickens J. Toward an anatomy of disappointment: reward-related signals from the globus pallidus. Neuron 2008;60:530-531.

128. Matsumoto M, Hikosaka O. Negative motivational control of saccadic eye movement by the lateral habenula. Prog Brain Res 2008;171:399-402.

129. Hikosaka O, Sesack SR, Lecourtier L, Shepard PD. Habenula: crossroad between the basal ganglia and the limbic system. J Neurosci 2008;28:11825-11829.

130. Matsumoto M, Hikosaka O. Lateral habenula as a source of negative reward signals in dopamine neurons. Nature 2007;447:1111-1115.

131. Ji H, Shepard PD. Lateral habenula stimulation inhibits rat midbrain dopamine neurons through a GABA(A) receptor-mediated mechanism. J Neurosci 2007;27:6923-6930.

132. Braak H, Del Tredici K, Rub U, de Vos RA, Jansen Steur EN, Braak E. Staging of brain pathology related to sporadic Parkinson's disease. Neurobiol Aging 2003;24:197-211.

133. Hirsch EC, Graybiel AM, Duyckaerts C, Javoy-Agid F. Neuronal loss in the pedunculopontine tegmental nucleus in Parkinson disease and in progressive supranuclear palsy. Proc Natl Acad Sci U S A 1987;84:5976-5980.

134. Karachi C, Grabli D, Bernard FA, et al. Cholinergic mesencephalic neurons are involved in gait and postural disorders in Parkinson disease. J Clin Invest 2010;120:2745-2754.

135. Rinne JO, Ma SY, Lee MS, Collan Y, Roytta M. Loss of cholinergic neurons in the pedunculopontine nucleus in Parkinson's disease is related to disability of the patients. Parkinsonism Relat Disord 2008; 14:553-557.

136. Pienaar IS, Elson JL, Racca C, Nelson G, Turnbull DM, Morris $\mathrm{CM}$. Mitochondrial abnormality associates with type-specific neuronal loss and cell morphology changes in the pedunculopontine nucleus in Parkinson disease. Am J Pathol 2013;183:1826-1840.

137. Alam M, Schwabe K, Krauss JK. The pedunculopontine nucleus area: critical evaluation of interspecies differences relevant for its use as a target for deep brain stimulation. Brain 2011;134:11-23.

138. Garcia-Rill E, Hyde J, Kezunovic N, Urbano FJ, Petersen E. The physiology of the pedunculopontine nucleus: implications for deep brain stimulation. J Neural Transm 2015;122:225-235.

139. Muller ML, Bohnen NI. Cholinergic dysfunction in Parkinson's disease. Curr Neurol Neurosci Rep 2013;13:377.

140. Crossman AR, Mitchell IJ, Sambrook MA. Regional brain uptake of 2-deoxyglucose in N-methyl-4-phenyl-1,2,3,6tetrahydropyridine (MPTP)-induced parkinsonism in the macaque monkey. Neuropharmacol 1985;24:587-591.

141. Schwartzman RJ, Alexander GM. Changes in the local cerebral metabolic rate for glucose in the 1-methyl-4-phenyl-1,2,3,6tetrahydropyridine (MPTP) primate model of Parkinson's disease. Brain Res 1985;358:137-143.

142. Filion M, Tremblay L, Bedard PJ. Abnormal influences of passive limb movement on the activity of globus pallidus neurons in parkinsonian monkeys. Brain Res 1988;444:165-176.

143. Miller WC, DeLong MR. Altered tonic activity of neurons in the globus pallidus and subthalamic nucleus in the primate MPTP model of parkinsonism. In: Carpenter MB, Jayaraman A (eds) The basal ganglia II. New York: Plenum Press; 1987. pp. 415-427.

144. Bergman H, Wichmann T, Karmon B, DeLong MR. The primate subthalamic nucleus. II. Neuronal activity in the MPTP model of parkinsonism. J Neurophys 1994;72:507-520.

145. Wichmann T, Bergman H, Starr PA, Subramanian T, Watts RL, DeLong MR. Comparison of MPTP-induced changes in spontaneous neuronal discharge in the internal pallidal segment and in the substantia nigra pars reticulata in primates. Exp Brain Res 1999;125:397-409.
146. Galvan A, Devergnas A, Wichmann T. Alterations in neuronal activity in basal ganglia-thalamocortical circuits in the parkinsonian state. Front Neuroanat 2015;9:5.

147. Wichmann T, Soares J. Neuronal firing before and after burst discharges in the monkey basal ganglia is predictably patterned in the normal state and altered in parkinsonism. J Neurophys 2006;95:2120-2133.

148. Zirh TA, Lenz FA, Reich SG, Dougherty PM. Patterns of bursting occurring in thalamic cells during parkinsonian tremor. Neurosci 1998;83:107-121.

149. Urbain N, Rentero N, Gervasoni D, Renaud B, Chouvet G. The switch of subthalamic neurons from an irregular to a bursting pattern does not solely depend on their GABAergic inputs in the anesthetic-free rat. J Neurosci 2002;22:8665-8675.

150. Chan V, Starr PA, Turner RS. Bursts and oscillations as independent properties of neural activity in the parkinsonian globus pallidus internus. Neurobiol Dis 2011;41:2-10.

151. Gatev P, Darbin O, Wichmann T. Oscillations in the basal ganglia under normal conditions and in movement disorders. Mov Disord 2006;21:1566-1577.

152. Hammond C, Bergman H, Brown P. Pathological synchronization in Parkinson's disease: networks, models and treatments. Trends Neurosci 2007;30:357-364.

153. Pasquereau B, Turner RS. Primary motor cortex of the parkinsonian monkey: differential effects on the spontaneous activity of pyramidal tract-type neurons. Cereb Cortex 2011;21:1362-1378.

154. Filion M, Tremblay L. Abnormal spontaneous activity of globus pallidus neurons in monkeys with MPTP-induced parkinsonism. Brain Res 1991;547:142-151.

155. Wichmann T, DeLong MR. Basal ganglia discharge abnormalities in Parkinson's disease. J Neural Transm Suppl 200;70:21-25.

156. Miguelez C, Morin S, Martinez A, et al. Altered pallido-pallidal synaptic transmission leads to aberrant firing of globus pallidus neurons in a rat model of Parkinson's disease. J Physiol 2012;590: 5861-5875.

157. Chu HY, Atherton JF, Wokosin D, Surmeier DJ, Bevan MD Heterosynaptic regulation of external globus pallidus inputs to the subthalamic nucleus by the motor cortex. Neuron 2015;85: 364-376.

158. Fan KY, Baufreton J, Surmeier DJ, Chan CS, Bevan MD. Proliferation of external globus pallidus-subthalamic nucleus synapses following degeneration of midbrain dopamine neurons. J Neurosci 2012;32:13718-13728.

159. Terman D, Rubin JE, Yew AC, Wilson CJ. Activity patterns in a model for the subthalamopallidal network of the basal ganglia. J Neurosci 2002;22:2963-2976.

160. Bevan MD, Magill PJ, Terman D, Bolam JP, Wilson CJ. Move to the rhythm: oscillations in the subthalamic nucleus-external globus pallidus network. Trends Neurosci 2002;25:525-531.

161. Lourens MA, Meijer HG, Contarino MF, et al. Functional neuronal activity and connectivity within the subthalamic nucleus in Parkinson's disease. Clin Neurophysiol 2013;124:967-981.

162. Brown P, Williams D. Basal ganglia local field potential activity: character and functional significance in the human. Clin Neurophysiol 2005;116:2510-2519.

163. Feng H, Zhuang P, Hallett M, Zhang Y, Li J, Li Y. Characteristics of subthalamic oscillatory activity in parkinsonian akinetic-rigid type and mixed type. Int J Neurosci 2015:1-10.

164. Dupre KB, Cruz AV, McCoy AJ, et al. Effects of L-dopa priming on cortical high beta and high gamma oscillatory activity in a rodent model of Parkinson's disease. Neurobiol Dis 2016;86:1-15.

165. de Hemptinne C, Ryapolova-Webb ES, Air EL, et al. Exaggerated phase-amplitude coupling in the primary motor cortex in Parkinson disease. Proc Natl Acad Sci U S A 2013;110:4780-4785. 
166. Ingham CA, Hood SH, Taggart P, Arbuthnott GW. Plasticity of synapses in the rat neostriatum after unilateral lesion of the nigrostriatal dopaminergic pathway. J Neurosci 1998;18:4732-4743.

167. Day M, Wang Z, Ding J, et al. Selective elimination of glutamatergic synapses on striatopallidal neurons in Parkinson disease models. Nat Neurosci 2006;9:251-259.

168. Deutch AY. Striatal plasticity in parkinsonism: dystrophic changes in medium spiny neurons and progression in Parkinson's disease. $\mathrm{J}$ Neural Transm Suppl 2006:67-70.

169. Raju DV, Ahern TH, Shah DJ, et al. Differential synaptic plasticity of the corticostriatal and thalamostriatal systems in an MPTPtreated monkey model of parkinsonism. Eur J Neurosci 2008;27: 1647-1658.

170. Villalba RM, Smith Y. Striatal spine plasticity in Parkinson's disease. Front Neuroanat 2010;4:133.

171. Villalba RM, Smith Y. Differential structural plasticity of corticostriatal and thalamostriatal axo-spinous synapses in MPTP-treated Parkinsonian monkeys. J Comp Neurol 2011;519:989-1005.

172. Villalba RM, Smith Y. Differential striatal spine pathology in Parkinson's disease and cocaine addiction: a key role of dopamine? Neurosci 2013;251:2-20.

173. Mathai A, Ma Y, Pare JF, Villalba RM, Wichmann T, Smith Y. Reduced cortical innervation of the subthalamic nucleus in MPTPtreated parkinsonian monkeys. Brain 2015;138:946-962.

174. Chu H-Y, Bevan MD. Long-term potentiation of external globus pallidus-subthalamic nucleus synapses following activation of motor cortical inputs. Soc Neurosci Ann Meeting Abstr 2013;270:13.

175. Hallett M. Parkinson's disease tremor: pathophysiology. Parkinsonism Relat Disord 2012;18(Suppl. 1):S85-S86.

176. Wu T, Hallett M. The cerebellum in Parkinson's disease. Brain 2013;136:696-709.

177. Mure H, Hirano S, Tang CC, et al. Parkinson's disease tremorrelated metabolic network: characterization, progression, and treatment effects. Neuroimage 2011;54:1244-1253.

178. Klein JC, Barbe MT, Seifried C, et al. The tremor network targeted by successful VIM deep brain stimulation in humans. Neurology 2012;78:787-795.

179. Hariz MI, Krack P, Alesch F, et al. Multicentre European study of thalamic stimulation for parkinsonian tremor: a 6 year follow-up. J Neurol Neurosurg Psychiatry 2008;79:694-699.

180. Albanese A, Bhatia K, Bressman SB, et al. Phenomenology and classification of dystonia: a consensus update. Mov Disord 2013;28:863-873.

181. Ozelius LJ, Hewett J, Kramer P, et al. Fine localization of the torsion dystonia gene (DYT1) on human chromosome 9q34: YAC map and linkage disequilibrium. Genome Res 1997;7:483-494.

182. Quartarone A, Hallett M. Emerging concepts in the physiological basis of dystonia. Mov Disord 2013;28:958-967.

183. Wichmann T. Commentary: Dopaminergic dysfunction in DYT1 dystonia. Exp Neurol 2008;212:242-246.

184. Augood SJ, Hollingsworth Z, Albers DS, et al. Dopamine transmission in DYT1 dystonia: a biochemical and autoradiographical study. Neurology 2002;59:445-448.

185. Balcioglu A, Kim MO, Sharma N, Cha JH, Breakefield XO, Standaert DG. Dopamine release is impaired in a mouse model of DYT1 dystonia. J Neurochem 2007;102:783-788.

186. Zhao Y, Decuypere M, Ledoux MS. Abnormal motor function and dopamine neurotransmission in DYT1 DeltaGAG transgenic mice. Exp Neurol 2008;210:719-730.

187. Pisani A, Bernardi G, Ding J, Surmeier DJ. Re-emergence of striatal cholinergic interneurons in movement disorders. Trends Neurosci 2007;30:545-553.

188. Pisani A, Martella G, Tscherter A, et al. Altered responses to dopaminergic $\mathrm{D} 2$ receptor activation and $\mathrm{N}$-type calcium currents in striatal cholinergic interneurons in a mouse model of DYT1 dystonia. Neurobiol Dis 2006;24:318-325.

189. Sciamanna G, Bonsi P, Tassone A, et al. Impaired striatal D2 receptor function leads to enhanced GABA transmission in a mouse model of DYT1 dystonia. Neurobiol Dis 2009;34:133-145.

190. Perlmutter JS, Tempel LW, Black KJ, Parkinson D, Todd RD. MPTP induces dystonia and parkinsonism. Clues to the pathophysiology of dystonia. Neurology 1997;49:1432-1438.

191. Tabbal SD, Mink JW, Antenor JA, Carl JL, Moerlein SM, Perlmutter JS. 1-Methyl-4-phenyl-1,2,3,6-tetrahydropyridine-induced acute transient dystonia in monkeys associated with low striatal dopamine. Neurosci 2006;141:1281-1287.

192. Ma Y, Hu X, Jinnah HA, Galvan A, Smith Y, Wichmann T. Induction of abnormal movements by MPTP treatment in infant rhesus monkeys. Soc Neurosci Abstr 2010.

193. Mitchell IJ, Luquin R, Boyce S, et al. Neural mechanisms of dystonia: evidence from a 2-deoxyglucose uptake study in a primate model of dopamine agonist-induced dystonia. Mov Disord 1990;5:49-54.

194. Hantraye P, Riche D, Maziere M, Isacson O. A primate model of Huntington's disease: behavioral and anatomical studies of unilateral excitotoxic lesions of the caudate-putamen in the baboon. Exp Neurol 1990;108:91-104.

195. Gerlach J, Hansen L. Clozapine and D1/D2 antagonism in extrapyramidal functions. BrJPychiatr 1997;17(Suppl.):34-37.

196. Casey DE. Dopamine D1 (SCH 23390) and D2 (haloperidol) antagonists in drug-naive monkeys. Psychopharmacol (Berlin) 1992;107:18-22.

197. Vitek JL, Chockkan V, Zhang JY, et al. Neuronal activity in the basal ganglia in patients with generalized dystonia and hemiballismus. Ann Neurol 1999;46:22-35.

198. Vitek JL. Pathophysiology of dystonia: a neuronal model. Mov Disord 2002;17(Suppl. 3):S49-S62.

199. Lenz FA, Suarez JI, Metman LV, et al. Pallidal activity during dystonia: somatosensory reorganisation and changes with severity. J Neurol Neurosurg Psychiatry 1998;65:767-770.

200. Zhuang P, Li Y, Hallett M. Neuronal activity in the basal ganglia and thalamus in patients with dystonia. Clin Neurophysiol 2004;115:2542-2557.

201. Starr PA, Rau GM, Davis V, et al. Spontaneous pallidal neuronal activity in human dystonia: comparison with Parkinson's disease and normal macaque. J Neurophys 2005;93:3165-3176.

202. Tang JK, Moro E, Mahant N, et al. Neuronal firing rates and patterns in the globus pallidus internus of patients with cervical dystonia differ from those with Parkinson's disease. J Neurophys 2007;98:720-729.

203. Hamada I, DeLong MR. Excitotoxic acid lesions of the primate subthalamic nucleus result in reduced pallidal neuronal activity during active holding. J Neurophysiol 1992;68:1859-1566.

204. Zhuang P, Hallett M, Zhang X, Li J, Zhang Y, Li Y. Neuronal activity in the globus pallidus internus in patients with tics. $\mathrm{J}$ Neurol Neurosurg Psychiatry 2009;80:1075-1081.

205. Lenz FA, Jaeger CJ, Seike MS, et al. Thalamic single neuron activity in patients with dystonia: dystonia-related activity and somatic sensory reorganization. J Neurophys 1999;82:2372-2392.

206. Silberstein P, Kuhn AA, Kupsch A, et al. Patterning of globus pallidus local field potentials differs between Parkinson's disease and dystonia. Brain 2003;126:2597-2608.

207. Chen CC, Kuhn AA, Hoffmann KT, et al. Oscillatory pallidal local field potential activity correlates with involuntary EMG in dystonia. Neurology 2006;66:418-420.

208. Miocinovic S, de Hemptinne C, Qasim S, Ostrem JL, Starr PA. Patterns of cortical synchronization in isolated dystonia compared with Parkinson disease. JAMA Neurol 2015;72:1244-1251.

209. Jinnah HA, Hess EJ. A new twist on the anatomy of dystonia: the basal ganglia and the cerebellum? Neurology 2006;67:1740-1741. 
210. Calderon DP, Fremont R, Kraenzlin F, Khodakhah K. The neural substrates of rapid-onset Dystonia-Parkinsonism. Nat Neurosci 2011;14:357-365.

211. Argyelan M, Carbon M, Niethammer M, et al. Cerebellothalamocortical connectivity regulates penetrance in dystonia. J Neurosci 2009;29:9740-9747.

212. Carbon M, Niethammer M, Peng S, et al. Abnormal striatal and thalamic dopamine neurotransmission: Genotype-related features of dystonia. Neurology 2009;72:2097-2103.

213. Ulug AM, Vo A, Argyelan M, et al. Cerebellothalamocortical pathway abnormalities in torsinA DYT1 knock-in mice. Proc Natl Acad Sci U S A 2011;108:6638-6643.

214. Prudente CN, Pardo CA, Xiao J, et al. Neuropathology of cervical dystonia. Exp Neurol 2013;241:95-104.

215. Bronstein JM, Tagliati M, Alterman RL, et al. Deep brain stimulation for Parkinson disease: an expert consensus and review of key issues. Arch Neurol 2010;68:165-171.

216. Okun MS, Fernandez HH, Wu SS, et al. Cognition and mood in Parkinson's disease in subthalamic nucleus versus globus pallidus interna deep brain stimulation: the COMPARE trial. Ann Neurol 2009;65:586-595.

217. Zahodne LB, Okun MS, Foote KD, et al. Greater improvement in quality of life following unilateral deep brain stimulation surgery in the globus pallidus as compared to the subthalamic nucleus. $\mathrm{J}$ Neurol 2009;256:1321-1329.

218. Locke MC, Wu SS, Foote KD, et al. Weight changes in subthalamic nucleus vs globus pallidus internus deep brain stimulation: results from the COMPARE Parkinson disease deep brain stimulation cohort. Neurosurgery 2011;68:1233-1237.

219. Follett KA, Weaver FM, Stern M, et al. Pallidal versus subthalamic deep-brain stimulation for Parkinson's disease. N Engl J Med 2010;362:2077-2091.

220. Weaver FM, Follett KA, Stern M, et al. Randomized trial of deep brain stimulation for Parkinson disease: thirty-six-month outcomes. Neurology 2012;79:55-65.

221. Odekerken VJ, van Laar T, Staal MJ, et al. Subthalamic nucleus versus globus pallidus bilateral deep brain stimulation for advanced Parkinson's disease (NSTAPS study): a randomised controlled trial. Lancet Neurol 2013;12:37-44.

222. Collomb-Clerc A, Welter ML. Effects of deep brain stimulation on balance and gait in patients with Parkinson's disease: A systematic neurophysiological review. Neurophysiol Clin 2015;45:371-388.

223. Williams NR, Foote KD, Okun MS. STN vs. GPi deep brain stimulation: translating the rematch into clinical practice. Mov Disord Clin Pract 2014;1:24-35.

224. Castrioto A, Moro E. New targets for deep brain stimulation treatment of Parkinson's disease. Expert Rev Neurother 2013;13:1319-1328.

225. Castrioto A, Lhommee E, Moro E, Krack P. Mood and behavioural effects of subthalamic stimulation in Parkinson's disease. Lancet Neurol 2014;13:287-305.

226. Mazzone P, Lozano A, Stanzione P, et al. Implantation of human pedunculopontine nucleus: a safe and clinically relevant target in Parkinson's disease. Neuroreport 2005;16:1877-1881.

227. Nosko D, Ferraye MU, Fraix V, et al. Low-frequency versus highfrequency stimulation of the pedunculopontine nucleus area in Parkinson's disease: a randomised controlled trial. J Neurol Neurosurg Psychiatry 2015;86:674-679.

228. Mazzone P, Insola A, Sposato S, Scarnati E. The deep brain stimulation of the pedunculopontine tegmental nucleus. Neuromodulation 2009;12:191-204.

229. Stefani A, Lozano AM, Peppe A, et al. Bilateral deep brain stimulation of the pedunculopontine and subthalamic nuclei in severe Parkinson's disease. Brain 2007;130:1596-1607.

230. Mazzone P, Sposato S, Insola A, Dilazzaro V, Scarnati E. Stereotactic surgery of nucleus tegmenti pedunculopontine. Br J Neurosurg 2008;22(Suppl. 1):S33-S40.
231. Ferraye MU, Debu B, Fraix V, et al. Effects of pedunculopontine nucleus area stimulation on gait disorders in Parkinson's disease. Brain 2010;133:205-214.

232. Khan S, Mooney L, Plaha P, et al. Outcomes from stimulation of the caudal zona incerta and pedunculopontine nucleus in patients with Parkinson's disease. Br J Neurosurg 2011;25:273-280.

233. Thevathasan W, Coyne TJ, Hyam JA, et al. Pedunculopontine nucleus stimulation improves gait freezing in Parkinson disease. Neurosurgery 2011;69:1248-1253.

234. Fasano A, Aquino CC, Krauss JK, Honey CR, Bloem BR. Axial disability and deep brain stimulation in patients with Parkinson disease. Nat Rev Neurol 2015;11:98-110.

235. Moro E, Hamani C, Poon YY, et al. Unilateral pedunculopontine stimulation improves falls in Parkinson's disease. Brain 2010;133: 215-224.

236. Mazzone P, Paoloni M, Mangone M, et al. Unilateral deep brain stimulation of the pedunculopontine tegmental nucleus in idiopathic Parkinson's disease: effects on gait initiation and performance. Gait Posture 2014;40:357-362.

237. Khan S, Javed S, Mooney L, et al. Clinical outcomes from bilateral versus unilateral stimulation of the pedunculopontine nucleus with and without concomitant caudal zona incerta region stimulation in Parkinson's disease. Br J Neurosurg 2012;26:722-725.

238. Khan S, Gill SS, Mooney L, et al. Combined pedunculopontinesubthalamic stimulation in Parkinson disease. Neurology 2012;78: 1090-1095.

239. Schrader C, Seehaus F, Capelle HH, Windhagen A, Windhagen H, Krauss JK. Effects of pedunculopontine area and pallidal DBS on gait ignition in Parkinson's disease. Brain Stim 2013;6:856-859.

240. Hamani C, Moro E, Lozano AM. The pedunculopontine nucleus as a target for deep brain stimulation. J Neural Transm 2011;118: 1461-1468.

241. Mazzone P, Sposato S, Insola A, Scarnati E. The clinical effects of deep brain stimulation of the pedunculopontine tegmental nucleus in movement disorders may not be related to the anatomical target, leads location, and setup of electrical stimulation. Neurosurgery 2013;73:894-906.

242. Fasano A, Lozano AM. Deep brain stimulation for movement disorders: 2015 and beyond. Curr Opin Neurol 2015;28:423-436.

243. Kupsch A, Benecke R, Muller J, et al. Pallidal deep-brain stimulation in primary generalized or segmental dystonia. N Engl J Med 2006;355:1978-1990.

244. Sako W, Goto S, Shimazu H, et al. Bilateral deep brain stimulation of the globus pallidus internus in tardive dystonia. Mov Disord 2008;23:1929-1931.

245. Capelle HH, Blahak C, Schrader C, et al. Chronic deep brain stimulation in patients with tardive dystonia without a history of major psychosis. Mov Disord 2010;25:1477-1481.

246. Chang EF, Schrock LE, Starr PA, Ostrem JL. Long-term benefit sustained after bilateral pallidal deep brain stimulation in patients with refractory tardive dystonia. Stereotact Funct Neurosurg 2010;88:304-310.

247. Gruber D, Trottenberg T, Kivi A, et al. Long-term effects of pallidal deep brain stimulation in tardive dystonia. Neurology 2009;73:53-58.

248. Shaikh AG, Mewes K, DeLong MR, et al. Temporal profile of improvement of tardive dystonia after globus pallidus deep brain stimulation. Parkinsonism Relat Disord 2015;21:116-119.

249. Rughani AI, Lozano AM. Surgical treatment of myoclonus dystonia syndrome. Mov Disord 2013;28:282-287.

250. Rocha H, Linhares P, Chamadoira C, Rosas MJ, Vaz R. Early deep brain stimulation in patients with myoclonus-dystonia syndrome. $\mathrm{J}$ Clin Neurosci 2016 Jan 22 [Epub ahead of print].

251. Kurtis MM, San Luciano M, Yu Q, et al. Clinical and neurophysiological improvement of SGCE myoclonus-dystonia with GPi deep brain stimulation. Clin Neurol Neurosurg 2010;112:149-152. 
252. Gruber D, Kuhn AA, Schoenecker T, et al. Pallidal and thalamic deep brain stimulation in myoclonus-dystonia. Mov Disord 2010;25:1733-1743.

253. Beukers RJ, Contarino MF, Speelman JD, Schuurman PR, Booij J, Tijssen MA. Deep brain stimulation of the pallidum is effective and might stabilize striatal $\mathrm{D}(2)$ receptor binding in myoclonusdystonia. Front Neurol 2012;3:22.

254. Welter ML, Grabli D, Vidailhet M. Deep brain stimulation for hyperkinetics disorders: dystonia, tardive dyskinesia, and tics. Curr Opin Neurol 2010;23:420-425.

255. Fox MD, Alterman RL. Brain Stimulation for Torsion Dystonia. JAMA Neurol 2015;72:713-719.

256. Pastor-Gomez J, Hernando-Requejo V, Luengo-Dos Santos A, Pedrosa-Sanchez M, Sola RG. [Treatment of a case of generalised dystonia using subthalamic stimulation]. Rev Neurol 2003;37: 529-531.

257. Sun B, Chen S, Zhan S, Le W, Krahl SE. Subthalamic nucleus stimulation for primary dystonia and tardive dystonia. Acta Neurochir Suppl 2007;97:207-214.

258. Benabid AL, Koudsie A, Benazzouz A, et al. Deep brain stimulation for Parkinson's disease. Adv Neurol 2001;86:405-412.

259. Lyons KE, Pahwa R. Effects of bilateral subthalamic nucleus stimulation on sleep, daytime sleepiness, and early morning dystonia in patients with Parkinson disease. J Neurosurg 2006;104:502-505.

260. Chou KL, Hurtig HI, Jaggi JL, Baltuch GH. Bilateral subthalamic nucleus deep brain stimulation in a patient with cervical dystonia and essential tremor. Mov Disord 2005;20:377-380.

261. Ostrem JL, Racine CA, Glass GA, et al. Subthalamic nucleus deep brain stimulation in primary cervical dystonia. Neurology 2011;76:870-878.

262. Kleiner-Fisman G, Liang GS, Moberg PJ, et al. Subthalamic nucleus deep brain stimulation for severe idiopathic dystonia: impact on severity, neuropsychological status, and quality of life. J Neurosurg 2007;107:29-36.

263. Fukaya C, Katayama Y, Kano T, et al. Thalamic deep brain stimulation for writer's cramp. J Neurosurg 2007;107:977-982.

264. Cho CB, Park HK, Lee KJ, Rha HK. Thalamic deep brain stimulation for writer's cramp. J Korean Neurosurg Soc 2009;46:52-55.

265. Asahi T, Koh M, Kashiwazaki D, Kuroda S. Stereotactic neurosurgery for writer's cramp: report of two cases with an overview of the literature. Stereotact Funct Neurosurg 2014;92:405-411.

266. Agnesi F, Connolly AT, Baker KB, Vitek JL, Johnson MD. Deep brain stimulation imposes complex informational lesions. PLoS One 2013;8:e74462.

267. Temperli P, Ghika J, Villemure JG, Burkhard PR, Bogousslavsky J, Vingerhoets FJ. How do parkinsonian signs return after discontinuation of subthalamic DBS? Neurology 2003;60:78-81.

268. Ruge D, Cif L, Limousin P, et al. Longterm deep brain stimulation withdrawal: clinical stability despite electrophysiological instability. J Neurol Sci 2014;342:197-199.

269. Limousin P, Pollak P, Benazzouz A, et al. Effect of parkinsonian signs and symptoms of bilateral subthalamic nucleus stimulation. Lancet 1995;345:91-95.

270. Limousin P, Pollak P, Benazzouz A, et al. Bilateral subthalamic nucleus stimulation for severe Parkinson's disease. Mov Disord 1995;10:672-674.

271. Rodriguez-Oroz MC, Obeso JA, Lang AE, et al. Bilateral deep brain stimulation in Parkinson's disease: a multicentre study with 4 years follow-up. Brain 2005;128:2240-2249.

272. Dostrovsky JO, Levy R, Wu JP, Hutchison WD, Tasker RR, Lozano AM. Microstimulation-induced inhibition of neuronal firing in human globus pallidus. J Neurophys 2000;84:570-574.

273. Filali M, Hutchison WD, Palter VN, Lozano AM, Dostrovsky JO. Stimulation-induced inhibition of neuronal firing in human subthalamic nucleus. Exp Brain Res 2004;156:274-281.
274. Welter ML, Houeto JL, Bonnet AM, et al. Effects of highfrequency stimulation on subthalamic neuronal activity in parkinsonian patients. Arch Neurol 2004;61:89-96.

275. Meissner W, Leblois A, Hansel D, et al. Subthalamic high frequency stimulation resets subthalamic firing and reduces abnormal oscillations. Brain 2005;128:2372-2382.

276. McIntyre CC, Savasta M, Walter BL, Vitek JL. How does deep brain stimulation work? Present understanding and future questions. Journal of Clinical Neurophysiology 2004;21:40-50.

277. Kringelbach ML, Jenkinson N, Owen SL, Aziz TZ. Translational principles of deep brain stimulation. Nat Rev Neurosci 2007;8: 623-635.

278. Lee KH, Chang SY, Roberts DW, Kim U. Neurotransmitter release from high-frequency stimulation of the subthalamic nucleus. $\mathrm{J}$ Neurosurg 2004;101:511-517.

279. Chiken S, Nambu A. High-frequency pallidal stimulation disrupts information flow through the pallidum by GABAergic inhibition. J Neurosci 2013;33:2268-2280

280. Dostrovsky JO, Lozano AM. Mechanisms of deep brain stimulation. Mov Disord 2002;17 Suppl 3:S63-S68.

281. Ranck JB. Which elements are excited in electrical stimulation of mammalian central nervous system: A review. Brain Res 1975;98: 417-440.

282. Vitek JL. Mechanisms of deep brain stimulation: excitation or inhibition. Mov Disord 2002;17(Suppl. 3):S69-S72.

283. Hashimoto T, Elder CM, Okun MS, Patrick SK, Vitek JL. Stimulation of the subthalamic nucleus changes the firing pattern of pallidal neurons. J Neurosci 2003;23:1916-1923.

284. Vitek JL, Zhang J, Hashimoto T, Russo GS, Baker KB. External pallidal stimulation improves parkinsonian motor signs and modulates neuronal activity throughout the basal ganglia thalamic network. Exp Neurol 2012;233:581-586.

285. Grill WM, Snyder AN, Miocinovic S. Deep brain stimulation creates an informational lesion of the stimulated nucleus. Neuroreport 2004; 15:1137-1140.

286. Nambu A, Tokuno H, Hamada I, et al. Excitatory cortical inputs to pallidal neurons via the subthalamic nucleus in the monkey. J Neurophys 2000;84:289-300.

287. Zimnik AJ, Nora GJ, Desmurget M, Turner RS. Movementrelated discharge in the macaque globus pallidus during highfrequency stimulation of the subthalamic nucleus. J Neurosci 2015;35:3978-3989.

288. Fukuda M, Ghilardi MF, Carbon M, et al. Pallidal stimulation for parkinsonism: improved brain activation during sequence learning. Ann Neurol 2002;52:144-152.

289. van Wouwe NC, Ridderinkhof KR, van den Wildenberg WP, et al Deep brain stimulation of the subthalamic nucleus improves reward-based decision-learning in Parkinson's disease. Front Hum Neurosci 2011;5:30.

290. Wilkinson L, Beigi M, Lagnado DA, Jahanshahi M. Deep brain stimulation of the subthalamic nucleus selectively improves learning of weakly associated cue combinations during probabilistic classification learning in Parkinson's disease. Neuropsychology 2011;25:286-294.

291. Mure H, Tang CC, Argyelan M, et al. Improved sequence learning with subthalamic nucleus deep brain stimulation: evidence for treatment-specific network modulation. J Neurosci 2012;32: 2804-2813

292. Wilson CJ, Beverlin B, 2nd, Netoff T. Chaotic desynchronization as the therapeutic mechanism of deep brain stimulation. Front Syst Neurosci 2011;5:50.

293. Moran A, Stein E, Tischler H, Bar-Gad I. Decoupling neuronal oscillations during subthalamic nucleus stimulation in the parkinsonian primate. Neurobiol Dis 2012;45:583-590.

294. McConnell GC, So RQ, Hilliard JD, Lopomo P, Grill WM. Effective deep brain stimulation suppresses low-frequency 
network oscillations in the basal ganglia by regularizing neural firing patterns. J Neurosci 2012;32:15657-15668.

295. Xu WD, Russo GS, Hashimoto T, Zhang JY, Vitek JL. Subthalamic nucleus stimulation modulates thalamic neuronal activity. J Neurosci 2008;28:11916-11924.

296. Johnson MD, Vitek JL, McIntyre CC. Pallidal stimulation that improves parkinsonian motor symptoms also modulates neuronal firing patterns in primary motor cortex in the MPTP-treated monkey. Exp Neurol 2009;219:359-362.

297. McCairn KW, Turner RS. Pallidal stimulation suppresses pathological dysrhythmia in the parkinsonian motor cortex. J Neurophysiol 2015;113:2537-2548.

298. Devergnas A, Wichmann T. Cortical potentials evoked by deep brain stimulation in the subthalamic area. Front Syst Neurosci 2011;5:30.

299. Li S, Arbuthnott GW, Jutras MJ, Goldberg JA, Jaeger D. Resonant antidromic cortical circuit activation as a consequence of highfrequency subthalamic deep-brain stimulation. J Neurophys 2007;98:3525-3537.

300. Hanajima R, Ashby P, Lozano AM, Lang AE, Chen R. Single pulse stimulation of the human subthalamic nucleus facilitates the motor cortex at short intervals. J Neurophys 2004;92:1937-1943.

301. Kuriakose R, Saha U, Castillo G, et al. The nature and time course of cortical activation following subthalamic stimulation in Parkinson's disease. Cereb Cortex 2010;20:1926-1936.

302. Gradinaru V, Mogri M, Thompson KR, Henderson JM, Deisseroth $\mathrm{K}$. Optical deconstruction of parkinsonian neural circuitry. Science 2009;324:354-359.

303. Ashby P, Paradiso G, Saint-Cyr JA, Chen R, Lang AE, Lozano AM. Potentials recorded at the scalp by stimulation near the human subthalamic nucleus. Clin Neurophysiol 2001;112:431-437.

304. MacKinnon CD, Webb RM, Silberstein P, et al. Stimulation through electrodes implanted near the subthalamic nucleus activates projections to motor areas of cerebral cortex in patients with Parkinson's disease. Eur J Neurosci 2005;21:1394-1402.

305. Eusebio A, Pogosyan A, Wang S, et al. Resonance in subthalamocortical circuits in Parkinson's disease. Brain 2009;132:2139-2150.

306. Sutton AC, O'Connor KA, Pilitsis JG, Shin DS. Stimulation of the subthalamic nucleus engages the cerebellum for motor function in parkinsonian rats. Brain Struct Funct 2015;220:3595-3609.

307. Bronte-Stewart H, Barberini C, Koop MM, Hill BC, Henderson JM, Wingeier B. The STN beta-band profile in Parkinson's disease is stationary and shows prolonged attenuation after deep brain stimulation. Exp Neurol 2009;215:20-28.

308. Eusebio A, Thevathasan W, Doyle Gaynor L, et al. Deep brain stimulation can suppress pathological synchronisation in parkinsonian patients. J Neurol Neurosurg Psychiatry 2011;82:569-573.

309. Eusebio A, Cagnan H, Brown P. Does suppression of oscillatory synchronisation mediate some of the therapeutic effects of DBS in patients with Parkinson's disease? Front Integr Neurosci 2012;6:47.

310. de Hemptinne C, Swann NC, Ostrem JL, et al. Therapeutic deep brain stimulation reduces cortical phase-amplitude coupling in Parkinson's disease. Nat Neurosci 2015;18:779-786.

311. McCairn KW, Turner RS. Deep brain stimulation of the globus pallidus internus in the parkinsonian primate: local entrainment and suppression of low-frequency oscillations. J Neurophys 2009;101:1941-1960

312. Spieles-Engemann AL, Steece-Collier K, Behbehani MM, et al. Subthalamic nucleus stimulation increases brain derived neurotrophic factor in the nigrostriatal system and primary motor cortex. Journal of Parkinson's disease 2011:1:123-136.

313. Spieles-Engemann AL, Collier TJ, Sortwell CE. A functionally relevant and long-term model of deep brain stimulation of the rat subthalamic nucleus: advantages and considerations. Eur J Neurosci 2010;32:1092-1099.
314. Spieles-Engemann AL, Behbehani MM, Collier TJ, et al. Stimulation of the rat subthalamic nucleus is neuroprotective following significant nigral dopamine neuron loss. Neurobiol Dis 2010;39:105-115.

315. Wallace BA, Ashkan K, Heise CE, et al. Survival of midbrain dopaminergic cells after lesion or deep brain stimulation of the subthalamic nucleus in MPTP-treated monkeys. Brain 2007;130: 2129-2145.

316. Temel Y, Visser-Vandewalle V, Kaplan S, et al. Protection of nigral cell death by bilateral subthalamic nucleus stimulation. Brain Res 2006;1120:100-105

317. Vedam-Mai V, Gardner B, Okun MS, et al. Increased precursor cell proliferation after deep brain stimulation for Parkinson's disease: a human study. PLoS One 2014;9:e88770.

318. Marsden CD, Obeso JA. The functions of the basal ganglia and the paradox of stereotaxic surgery in Parkinson's disease. Brain 1994;117:877-897.

319. Desmurget M, Turner RS. Testing basal ganglia motor functions through reversible inactivations in the posterior internal globus pallidus. J Neurophys 2008;99:1057-1076.

320. Desmurget M, Turner RS. Motor sequences and the basal ganglia: kinematics, not habits. J Neurosci 2010;30:7685-7690.

321. Parent A. Comparative neurobiology of the basal ganglia. New York: John Wiley \& Sons 1986

322. Raz A, Vaadia E, Bergman H. Firing patterns and correlations of spontaneous discharge of pallidal neurons in the normal and the tremulous 1-methyl-4-phenyl-1,2,3,6-tetrahydropyridine vervet model of parkinsonism. J Neurosci 2000;20:8559-8571.

323. Raz A, Frechter-Mazar V, Feingold A, Abeles M, Vaadia E, Bergman H. Activity of pallidal and striatal tonically active neurons is correlated in mptp-treated monkeys but not in normal monkeys. J Neurosci 2001;21:RC128.

324. Goldberg JA, Boraud T, Maraton S, Haber SN, Vaadia E, Bergman $\mathrm{H}$. Enhanced synchrony among primary motor cortex neurons in the 1-methyl-4-phenyl-1,2,3,6-tetrahydropyridine primate model of Parkinson's disease. J Neurosci 2002;22:4639-4653.

325. Goldberg JA, Rokni U, Boraud T, Vaadia E, Bergman H. Spike synchronization in the cortex/basal-ganglia networks of Parkinsonian primates reflects global dynamics of the local field potentials. J Neurosci 2004;24:6003-6010.

326. Heimer G, Rivlin M, Israel Z, Bergman H. Synchronizing activity of basal ganglia and pathophysiology of Parkinson's disease. J Neural Transm Suppl 2006;70:17-20.

327. Heimer G, Bar-Gad I, Goldberg JA, Bergman H. Dopamine replacement therapy reverses abnormal synchronization of pallidal neurons in the 1-methyl-4-phenyl-1,2,3,6-tetrahydropyridine primate model of parkinsonism. J Neurosci 2002;22:7850-7855.

328. Stein E, Bar-Gad I. beta oscillations in the cortico-basal ganglia loop during parkinsonism. Exp Neurol 2013;245:52-59.

329. Brocker DT, Swan BD, Turner DA, et al. Improved efficacy of temporally non-regular deep brain stimulation in Parkinson's disease. Exp Neurol 2013;239:60-67.

330. Brocker DT, Grill WM. Principles of electrical stimulation of neural tissue. Handb Clin Neurol 2013;116:3-18.

331. Birdno MJ, Kuncel AM, Dorval AD, Turner DA, Gross RE, Grill WM. Stimulus features underlying reduced tremor suppression with temporally patterned deep brain stimulation. J Neurophysiol 2012;107:364-383.

332. Popovych OV, Tass PA. Control of abnormal synchronization in neurological disorders. Frontiers in neurology 2014;5:268.

333. Adamchic I, Hauptmann C, Barnikol UB, et al. Coordinated reset neuromodulation for Parkinson's disease: Proof-of-concept study. Mov Disord 2014;29:1679-1684.

334. Tass PA, Qin L, Hauptmann C, et al. Coordinated reset has sustained aftereffects in Parkinsonian monkeys. Ann Neurol 2012;72:816-820 
335. Rosin B, Slovik M, Mitelman R, et al. Closed-loop deep brain stimulation is superior in ameliorating parkinsonism. Neuron 2011;72:370-384.

336. Little S, Pogosyan A, Neal S, et al. Adaptive deep brain stimulation in advanced Parkinson disease. Ann Neurol 2013;74:449-457.

337. Pollo C, Kaelin-Lang A, Oertel MF, et al. Directional deep brain stimulation: an intraoperative double-blind pilot study. Brain 2014;137:2015-2026.
338. Keane M, Deyo S, Abosch A, Bajwa JA, Johnson MD. Improved spatial targeting with directionally segmented deep brain stimulation leads for treating essential tremor. J Neural Eng 2012;9: 046005.

339. Wichmann T. Pathophysiologic basis of movement disorders. In: Niranjan A, Lunsford LD, Richardson M (eds). Controversies in movement disorders. Progress in neurological surgery. Basel (Switzerland): S. Karger AG; 2016 (in press). 